\title{
Article
}

\section{What Happens in Your Brain When You Walk Down the Street? Implications of Architectural Proportions, Biophilia, and Fractal Geometry for Urban Science}

\author{
Aenne A. Brielmann ${ }^{1}\left(\mathbb{D}\right.$, Nir H. Buras ${ }^{2}$, Nikos A. Salingaros ${ }^{3, *} \mathbb{1}$ and Richard P. Taylor ${ }^{4}$ \\ 1 Department of Computational Neuroscience, Max-Planck Institute for Biological Cybernetics, \\ 72076 Tübingen, Germany; aenne.brielmann@tuebingen.mpg.de \\ 2 Classic Planning Institute, Washington, DC 20007, USA; nburas@classicplanning.com \\ 3 Departments of Mathematics and Architecture, University of Texas at San Antonio, One UTSA Circle, \\ San Antonio, TX 78249, USA \\ 4 Physics Department, University of Oregon, Eugene, OR 97405, USA; rpt@uoregon.edu \\ * Correspondence: salingar@gmail.com
}

\section{check for}

updates

Citation: Brielmann, A.A.; Buras, N.H.; Salingaros, N.A.; Taylor, R.P. What Happens in Your Brain When You Walk Down the Street? Implications of Architectural Proportions, Biophilia, and Fractal Geometry for Urban Science. Urban Sci. 2022, 6, 3. https://doi.org/ 10.3390/urbansci6010003

Academic Editor: Jesús Manuel González Pérez

Received: 5 November 2021 Accepted: 31 December 2021 Published: 7 January 2022

Publisher's Note: MDPI stays neutral with regard to jurisdictional claims in published maps and institutional affiliations.

Copyright: (C) 2022 by the authors. Licensee MDPI, Basel, Switzerland. This article is an open access article distributed under the terms and conditions of the Creative Commons Attribution (CC BY) license (https:// creativecommons.org/licenses/by/ $4.0 /)$.

\begin{abstract}
This article reviews current research in visual urban perception. The temporal sequence of the first few milliseconds of visual stimulus processing sheds light on the historically ambiguous topic of aesthetic experience. Automatic fractal processing triggers initial attraction/avoidance evaluations of an environment's salubriousness, and its potentially positive or negative impacts upon an individual. As repeated cycles of visual perception occur, the attractiveness of urban form affects the user experience much more than had been previously suspected. These perceptual mechanisms promote walkability and intuitive navigation, and so they support the urban and civic interactions for which we establish communities and cities in the first place. Therefore, the use of multiple fractals needs to reintegrate with biophilic and traditional architecture in urban design for their proven positive effects on health and well-being. Such benefits include striking reductions in observers' stress and mental fatigue. Due to their costs to individual well-being, urban performance, environmental quality, and climatic adaptation, this paper recommends that nontraditional styles should be hereafter applied judiciously to the built environment.
\end{abstract}

Keywords: biophilic design; design-attention; disengagement; engagement; eye-tracking; façades; fractals; interaction-design; neuroscience; public-space; traditional styles; urban design; Visual Attention Software

\section{Introduction and Background}

Since the first cities, human needs were the primary drivers in creating built environments. But following other directions and exigencies adopted since World War I, urban design nowadays often causes physical and psychological distress to humans, the environment, and the planet.

For over a century, planners and designers have been challenged by what to lay people is obvious - the necessity of biologically-based beauty, appropriate urban scale, and the possibility of extending or embellishing traditional environments without marring them. Today we know that aesthetics play a central role in judgments of built environments.

We aim to support civic and urban interaction through making beautiful cities. Evidence shows that understanding aesthetic experience requires biological underpinnings that help to explain how the aesthetic experience promotes better walkability and navigation. The present article necessarily mixes qualitative and quantitative approaches. We review here the quantitative evidence from psychology and neuroscience to substantiate qualitative claims about the necessary changes in how we design the built environment. 
While it is beyond the scope of this article to present novel quantitative data, we believe that a comprehensive survey of well-established results serves the purpose of this article best.

We argue that modernist design is not as satisfying as traditional and classical design. Anyone who has visited Barcelona, Lucca, or Rome, for example, can attest to their beauty. Their architecture encourages walking, although in Barcelona's Las Ramblas the trees contribute as much as the façades. In fact, the façades share a similar mathematical structure with the trees. Modernist facades-simplistic and stripped down-are not as pleasing, and lessen the sense of well-being. The myriad of visual impressions influence where we walk and how we feel while doing so.

Using philosopher John Dewey's definition of the aesthetic experience as a "peak experience" urban beauty can be identified as the most relevant measure of salutogenic environments. This is because of the manner in which the brain processes the visual environment, and the key influence of fractal patterns on both how the eyes scan the environments and what they pick up [1-6]. Fractals are patterns that repeat at increasingly fine sizes and so create shapes of rich visual complexity. Prevalent in nature, clouds, trees, and mountains are common examples, as are cauliflowers and fern leaves [1-3]. This paper dives into the complex minutiae of vision and fractals, and how they can place the observer in the "comfort zone". A novel scientific toolkit that this paper brings together can help to design the most healthful and useful urban environments long-term.

\section{Research Methodology}

\subsection{Factors That Influence the Use of Urban Space}

This paper focuses on gathering scientific data identifying the factors responsible for urban space utilization. We collected and summarized the relevant literature in several distinct fields. Our intention is to bypass the usual questionnaire-based surveys and to use only hard evidence obtained from mathematical and medical investigations. In this way, discovered "preferences" discussed here should be innate and biological, and not influenced by learning or other societal factors. We know from previous experience that a great deal of confusion about the proper design of urban space can arise if this distinction is not made.

The present review and synthesis aims to inspire future empirical experiments designed to confirm and quantify the positive impacts hypothesized in this paper. To that end, we review here current empirical research, extract its principal findings, and show how they relate to past and contemporary urban design principles. Based on the collective literature review, we jointly identified common themes that re-appeared in several fields, namely: fractal dimensionality, beauty or aesthetic pleasure, visual perceptual processing and their associations with well-being and movement or navigation in one's environment. From there, we derived the implications and processes associated with each of these major themes within the temporal sequence of walking down a street. Finally, we reviewed the thus gained insights and spelled out their implications for the future of architecture and urban design. Below, we briefly lay out the process that underlies the creation of this article.

\subsection{Data from Fractal Fluency}

The present study analyzes, reviews, and synthesizes the considerable literature on fractals. Many of those key results are due to the present authors, and link a type of fractal, and specifically the optimal range for the fractal dimension, to unconscious behavior that underlies human visual attraction. We identify how the fractal qualities of the surrounding visual environment either encourage or discourage movement and navigation in urban spaces. This effect, in turn, is responsible for feeling "at ease" in a pedestrian urban setting. Going beyond aesthetic attraction, fractal patterns of the right dimension are shown to exert a measurable healing effect on humans. We review results on this important mechanism, drawing from the medical literature. 


\subsection{Data from Eye-Scanning and Visual Simulation Software}

We discuss how the new data-gathering tool Visual Simulation Software (VAS) gives a color heat-map of where the eye spends its time in viewing a picture. This diagnostic tool is applied to evaluate an urban scene. We synthesize fractals and unconscious visual attention, arguing that a pedestrian will walk in a direction to which attention is drawn only when combined with a positive feeling (as ascertained from other data, not from the Visual Simulation Software). As detailed in our analysis, attention can also be unconsciously triggered by a threatening visual signal, and so it is important to distinguish positive (attractive) from negative (alarming) signals. We use existing data to show how engagement is essential for connecting emotionally and neurologically to the immediate surroundings, which then determines unconscious decisions on navigation and urban space use.

\subsection{Biologically-Based Beauty and the Sublime}

We review the factors contributing to the perception of "beauty" in an object or surroundings that arise from neurological responses in the body. This approach is entirely distinct from traditional aesthetic interpretations. We demonstrate, in an empirical manner, how distinguishing biological mechanisms for responses related to "beauty" from acquired or learned responses helps to clear up ambiguities that get in the way of good-that is, salutogenic-design of public spaces. We review results from the medical literature that establish healing properties of environments, and discuss how those correlate with definite characteristics: specifically, with particular Biophilic and geometrical qualities. We apply results from responses to fractals to identify, for the first time, the frightening visual architectural situations that are traditionally called "Sublime". By measuring the fractal dimension of the well-known drawings of Piranesi's imaginary prisons using box-counting software, we validate previous conjectural work on fractals that predicted a correlation between high $D$-values and an alarming (as opposed to a soothing) emotional effect.

\subsection{Universality of Neurological Responses to Visual Environments}

While this is never a point of debate in the medical and scientific professions, the architecture and design communities tend to hold the opposite viewpoint: that beauty is in the eye of the beholder. For this reason, we collect data establishing the neurological basis for common aesthetic responses to visual environments. The human body shows a common positive response to art, mathematical images, and natural scenery, establishing our claim for universality based on specific mathematical qualities. As a separate facet of universality, available data suggest that all people use the same unconscious mechanisms to process the visual characteristics of a group of designs and objects that are separately established as salutogenic. We demonstrate that the initial, unconscious positive response of people is indeed universal, as expected from the common physiological basis.

Individuals may, and do, vary in their later, conscious responses, but those occur on a different, longer time scale than the first engagement response. We review medical references that indicate stress-generation whenever the first neurological response is antithetical to the later response induced by learning.

\subsection{The Time Sequence of Neural Image Processing}

In our research, the framework's basic mechanism is a sequence of neurological events that occur in the viewer's brain. The time scale is on the order of milliseconds, hence those signals and subsequent decisions are unconscious. We synthesize data obtained from previous psychophysical experiments that show this. To implement our model, it was necessary to break down the processing path into four stages, covering the time period of 0 to $200 \mathrm{~ms}$. To this end, the enhanced methodology and perception stages are defined as one "perception cycle" with period approximately $300 \mathrm{~ms}$, which repeats as the pedestrian advances in any direction. We use recent experimental data to propose a correlation between the rhythms of ambulatory motion and the brain processing of information from the environment. 


\subsection{Literature Review and Supplemental Information}

Because the scientific information presented here does not yet form part of the standard literature of reference for urban design and planning, we have undertaken a fairly exhaustive literature survey. We provide a detailed overview of this literature review as Supplemental Information. The model presented in this paper depends in part on neuroaesthetics, which is a developing research discipline. We review research that establishes a strong link between pedestrian movement and hedonic experience, based on dopaminergic reward-related circuits in the brain. We also present data to establish thigmotaxis (motion along a wall for protection) and urban street edges, which consequently explains why those are the most visually engaged component of streets.

\section{Informational Decisions Direct the Act of Walking}

\subsection{Fractal Patterns and Visual Attention Software}

Fractal patterns impact human visual perception and processing early and at short time scales. The temporal sequence of the first milliseconds of visual stimulus processing reveals that within less than $100 \mathrm{~ms}$, the process that determines attraction or avoidance has already started (a full discussion of the temporal mechanism is given in the appropriate section below, together with the technical references) [6]. Bottom-up, "automated," first $150 \mathrm{~ms}$ perception precedes the subsequent top-down processing and intellection, which either leads to a positive experience or justifies a negative one. Most significantly, this initial evaluation informs people's navigation. While traditional urban objects such as doors, signs, windows, and stairs can be recognized rapidly, non-traditional designs simply do not register [4-6]. As far as the brain is concerned, the typically undistinguished glass front door to a modernist building is simply not there [4-6].

An extremely useful tool for predicting eye-tracking fixation points is now available in the Visual Attention Software (VAS) [4-6]. Using artificial intelligence to analyze and document tens of thousands of actual eye-scanning maps, the program was trained to predict where a person will look at in an image based solely on the image itself. The VAS manufacturer (3M Corporation) claims that these predictions are $92 \%$ accurate. It obviates having to employ actual eye-scanning monitor equipment, although this ought to be seen as a shortcut that does not in any way replace direct eye-tracking measurements.

In Figures 1 and 2, VAS heatmaps illustrate how eye-tracked visual scans of low-fractal architecture catch so little perceptual attention that they are barely-if at all-identified as built objects. The traditional tower beyond the portrayed stretch of the Aarhus River is more noticed than the massive buildings lining the River's concrete channel. The hotdog cart in front of iconic Guggenheim Museum in New York City is more visible than its front door! As a backdrop to the traffic light over the intersection, the museum's mass is not even noticed.

It is a human right to walk down beautiful streets; to enjoy the appropriate multiple fractal scaling in the built environment; to be protected from the negative psychological reaction caused by experiencing mute, Modernist boxes and bleak, boring facades, which eye tracking indicates as imperceptible to the visual system. Establishing what is "beautiful" and what is not is a monumental task. One component of biologically-based beauty is the relationship between fractals and preferred aesthetic response [1-3]. This is a result of many research groups working over decades, and hundreds more experiments are needed. This paper merely adds one piece to this major project for investigation, and collects a large number of references that contribute to establish the link between beauty and fractals. Our aim is different: to discuss the time sequence influencing the act of walking. Fractals play a part in our argument, but are not its sole focus. 


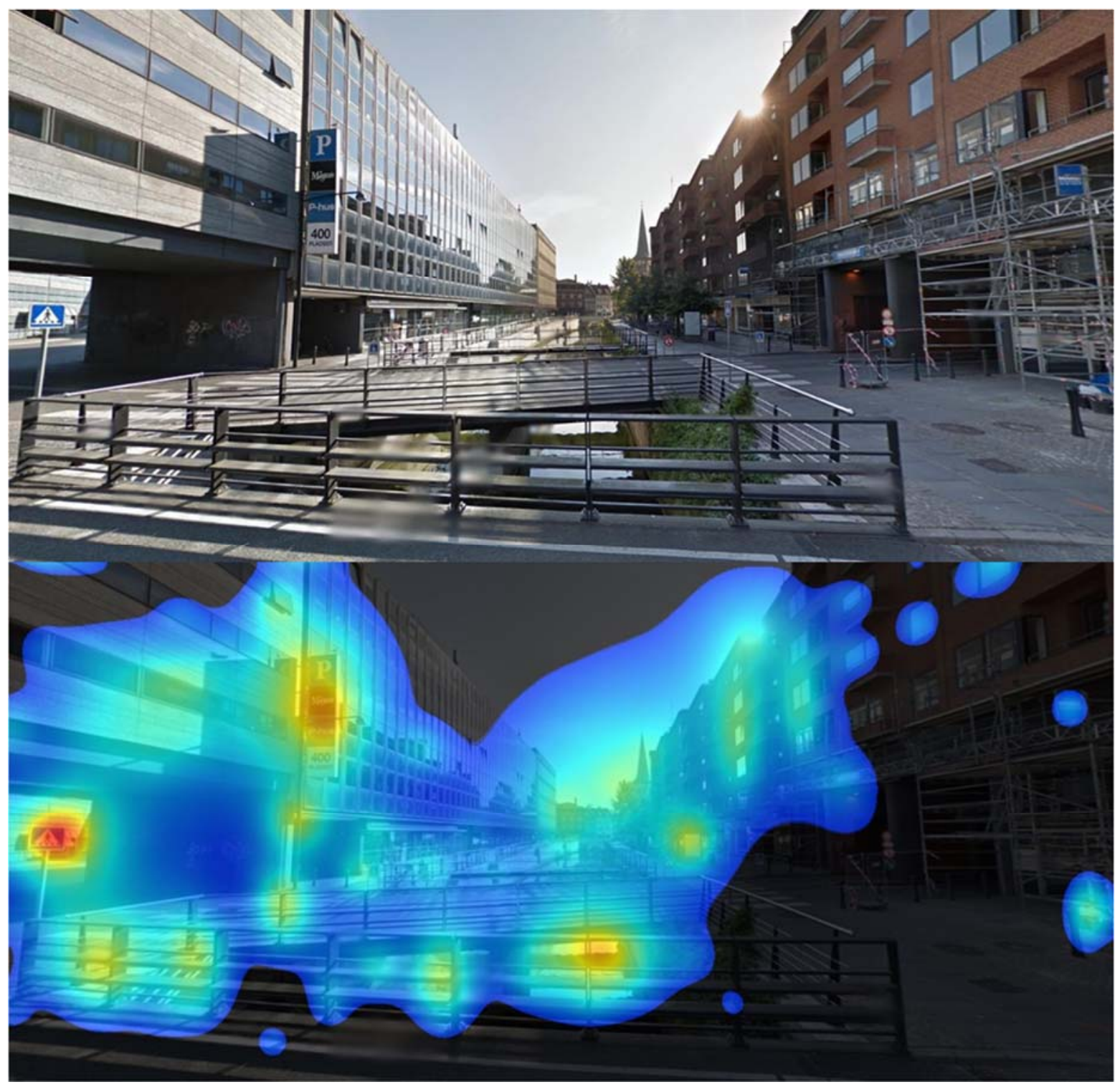

Figure 1. That which is perceived in a purely Modernist environment is perceptually meaningless. Top: The Center City Aarhus River is a functionalist concrete drainage channel set in an intolerably harsh cityscape. Image retrieved from Google Maps. Bottom: The Center City Aarhus River analyzed using 3M's Visual Attention Software (VAS). Eye tracking data and visualization by N. H. Buras.

Despite mounting evidence that familiar, fractal structures result in a more positive urban experience, leading 21st century planners and architects follow 20th century architectural ideology with the express goal of achieving notoriety and novelty. The result is that they eliminate the very properties that elicit human well-being in cities [7]. Contradicting the fundamental human drive to physically approach built environments that are aesthetically pleasing, contemporary architects insist on creating environments that challenge, rather than support, people's cognition.

But a naturally structured environment is easier for us to process. Being conducive to how we naturally process the world, it produces less strain on our perceptual and cognitive system. Because of their common fractal and other symmetries, a human brain seeing a classical/traditional building can process it as easily as a tree [8]. 


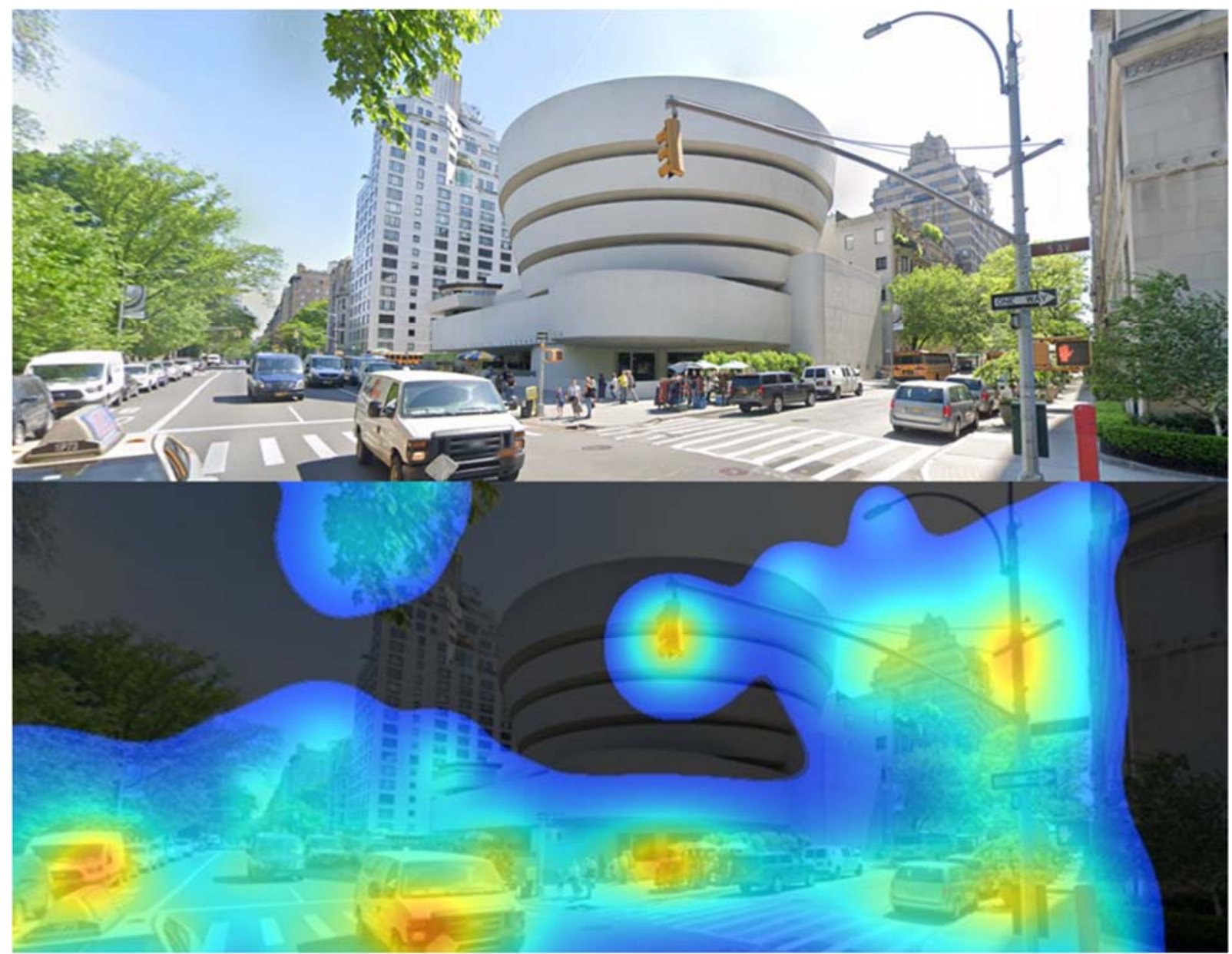

Figure 2. The Guggenheim Museum is "there," but its design is incomprehensible neuroaesthetically. Top: The Guggenheim Museum in New York City. Image retrieved from Google Maps. Bottom: The Guggenheim Museum analyzed using 3M's Visual Attention Software (VAS). Eye tracking data and visualization by N. H. Buras.

This paper calls for unambiguously using the "beautiful" in terms of neuroaesthetic biological responses rather than through aesthetic preference or art-historical terms. Its purpose is to help reclaim the appropriate and practical design toolkits that past generations possessed. In order to do so, the research gap that this paper is addressing is the relation between aesthetic experience, the fractal characteristics of built form, and the neural sequencing of that processing in real time. Assisted by the latest scientific understanding of perception, it is indeed possible to once again create legacies of beautiful places for the greatest well-being of the greatest number of people. Granted, modernist urbanism-with its automobile dependency and sprawling suburbs-is a bigger problem than façade design, but this must be addressed separately.

At the heart of our argument is the empirically grounded recognition that urban spaces strongly depend upon the architecture of the surrounding building façades [8,9]. Even though classical and traditional architects and planners have always known this fact and incorporated it into their designs, it is only now that the rest of the profession realizes that architecture and urbanism are not disconnected, because much of what one can see on a typical urban street consists of buildings [8], p. 256. The bottom line is that we had a highly adaptive urban design toolbox; we purposely lost it in pursuit of utopian dreams of a technological future. Now, we need to reclaim it, with multiple-fractal environments that lessen anxiety, bolster well-being, and boost individual performance. 


\subsection{Fractal Fluency and Restorative Environments}

Contemporary urban design practices have been shown to cause physical and psychological stress [3-10]. Indeed, the World Health Organization views stress to be the "Health epidemic of the 21st Century", with associated illnesses ranging from depression to schizophrenia [10]. What is not widely known is that the actual geometry of the physical surroundings, and the visual information it communicates, can contribute to stress [8]. This informational component of stress adds to the multiple other sources of stress encountered in everyday life.

Recognition of built environment stress prompted Jane Jacobs and Christopher Alexander [11,12] to call for human-centered design, and for Edward Wilson to promote Biophilia-nature-loving - which recognizes the inherent connection of humans to nature by means of perceived geometry [13].

Roger Ulrich and colleagues showed that exposure to natural scenery reduced stress significantly, and even accelerated patients' recovery from major surgery [14-16]. Kaplan and Kaplan proposed separately that the restorative power of 'soft' attention, induced by nature- different from the 'hard' attention required for learned tasks such as reading books and analyzing objects close-up-could restore depleted mental resources, reduce mental fatigue, and refresh the ability to concentrate, even preventing occupational burn-out.

Attention Restoration Theory claims that the capacity for directed attention on focused tasks that has been decreased with prolonged use can be restored by engaging in effortless aesthetic experience. With our capacity to engage in it unlimited, Nature particularly fosters this type of experience, as it can hold the attention effortlessly while leaving ample space "to think about other things" at the same time [17].

Inspired by such initial studies and propelled by Benoît Mandelbrot's exposition of the prevalence of fractal geometries in nature [18], a subsequent large body of psychology experiments sought to confirm that the aesthetic qualities of certain fractal patterns induced such positive effects [19-54].

Natural scenes typically feature a rich fractal content originating from several factors: (1) the fractal shapes of a range of individual objects, (2) the fractal distribution of sizes of these objects, (3) the fractal luminance textures within the objects, and (4) the fractal shapes formed when neighboring objects combine visually to create larger fractal composites.

Interestingly, traditional and classical architectures also capture all of these elements. In particular, point (4) contains the traditional designer's method of creating coherent compositions that bind different building parts and individual buildings into a visually harmonious context. In fact, much of the know-how regarding ways to enhance the user's emotional experience is inherent to the architectural literacy component of the classical design method and traditional architecture [8].

Indeed, "fractal fluency" conveys the notion stemming from evolutionary exposure, that the human visual system has become fluent in, and can efficiently process, the visual "language" of nature's multiple fractals [50]. Consequently, fractal images are collected through "effortless looking" and this induces a positive aesthetic experience along with an associated reduction in physiological stress. Such effortless looking underlies what happens in our brains when we walk down the street. Lutyens's New Delhi (Figure 3 Top) and the African Savannah (Figure 3 Bottom) share similar fractal dimensionalities (not computed here). The types and number of fractals required to create a positive aesthetic experience in the built environment have been enumerated elsewhere [8].

Giving a general idea of this measure, the fractal dimension $D$ quantifies how the patterns at different scales assemble into the fractal image. For simple and smooth (i.e., non-fractal) shapes, $D$ matches what we would expect for dimensionality: a smooth line has a $D$ value of 1 while a completely filled homogeneous area has a value of 2 . The repeating patterns embedded in a fractal line cause it to begin to occupy space. Accordingly, its $D$ value lies somewhere between 1 and 2 . The prevalence of mid- $D$ fractals in nature occurs for biological reasons (i.e., their functionality benefits from mid- $D$ ) rather than 
any statistical reason. Our cognitive system evolved to prefer the fractals that are most prevalent in nature, which happen to be in that mid 1.3-1.5 range.

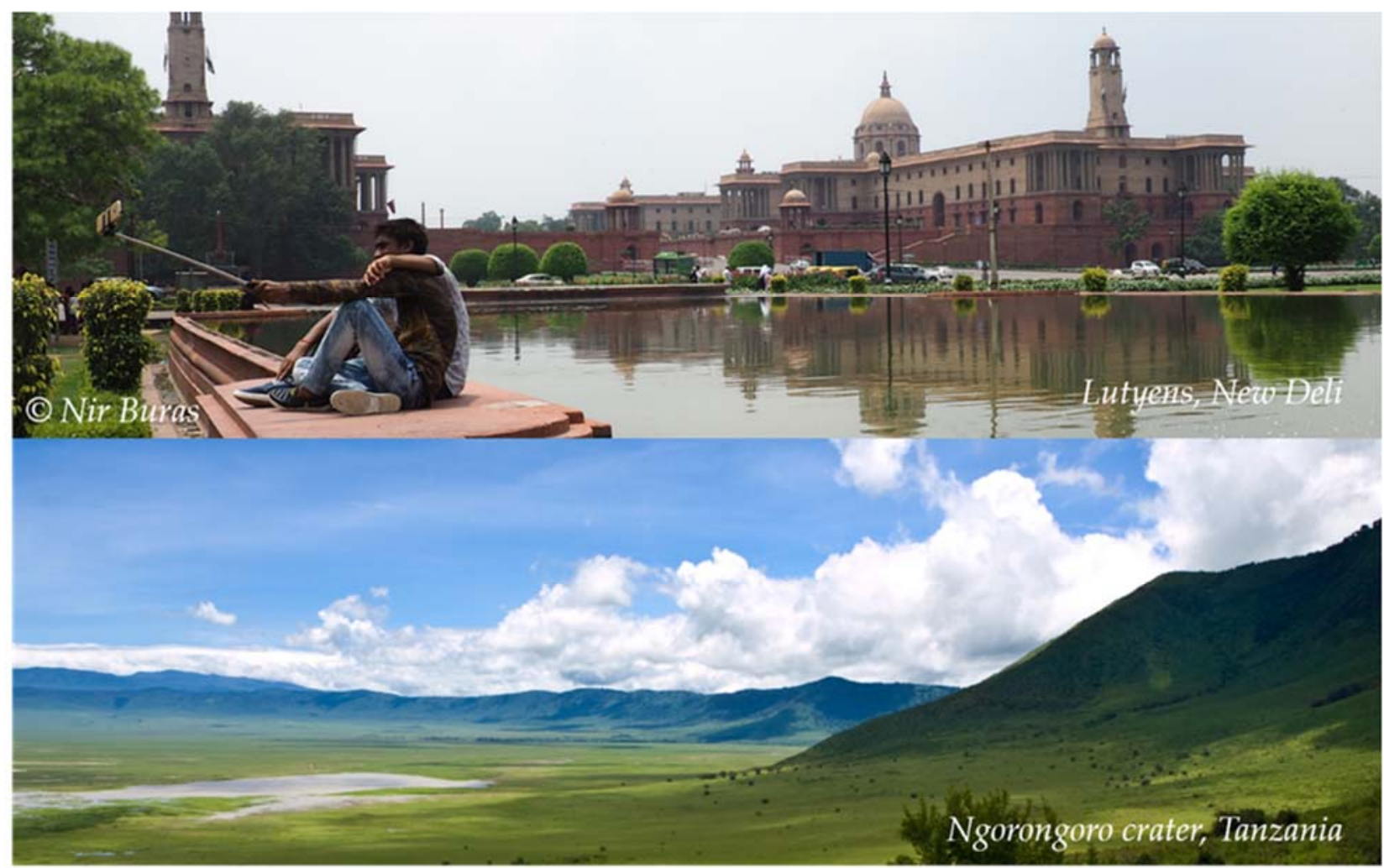

Figure 3. Lutyens's New Delhi (Top) and the African Savannah (Bottom) share fractal qualities, as opposed to the non-fractal plainness found in more modern buildings. Photos: New Delhi, Nir Buras; Ngorongoro Crater, William Warby, CC BY 2.0 Wikimedia Commons, https:/ / commons.wikimedia. org/wiki/File:Ngorongoro_Crater.jpg (accessed on 30 December 2021).

When the contribution of fine structure to this fractal mix is increased, the line gradually fills in the 2-dimensional surface of the retina and the visual fractal's $D$ value therefore approaches 2. Although there are examples of natural fractals with $D$ values from 1.1 to 1.9, the most common lie in the narrower range between 1.3 and 1.5. This is an experimental finding from measuring the $D$ value of various natural objects [8,22]. As examples, many clouds and trees lie in this range. This observation informs the fractal fluency model, which proposes that humans have adapted to efficiently process these mid-complexity patterns that determined the evolution of our perceptual system.

Experiments investigating qEEG (Quantitative Electroencephalogram) responses emphasize that the viewer's attention is being engaged by mid- $D$ fractals $[26,55]$. While engaged, fractal fluency improves the performance of visual tasks. For example, participants in behavioral studies exhibited increased sensitivity to mid- $D$ fractals and they could distinguish patterns' $D$ values more accurately [28]. Other pattern recognition capabilities also heighten for mid- $D$ fractals [50]. Associated improvements in spatial awareness lead to superior navigation through environments containing mid- $D$ fractals [29]. For example, when participants were instructed to navigate an avatar to find an object randomly placed within a virtual landscape, accuracy and completion speeds peaked for the mid-complexity landscapes predicted by the fluency model. These enhanced processing capabilities place the observer in their visual 'comfort zone' which in turn triggers stress reduction.

To avoid misunderstanding, the model of this paper does not rely on any particular value of the fractal dimension $D$ as an indicator that can be used to discriminate between beauty and sublime urban landscape. What is established as crucial is the difference be- 
tween the fractality of a more traditionally-designed façade (or a tree) and the lack of fractality in an industrial-modernist façade composed of a sheer, empty surface. Substantial previous work established that people prefer looking at scenes with intermediate fractal dimension $D$ [19-55], at least in art, mathematical images, and natural scenery [21]. We admit that the same preference does not yet have direct empirical support in urban landscapes. Given the 'universal' behavior across art, mathematics, and nature, however, transfer to this domain is a reasonable prediction. Figure 4 below demonstrates how intermediate $D$ values impact the visual look of a landscape-like scenery.
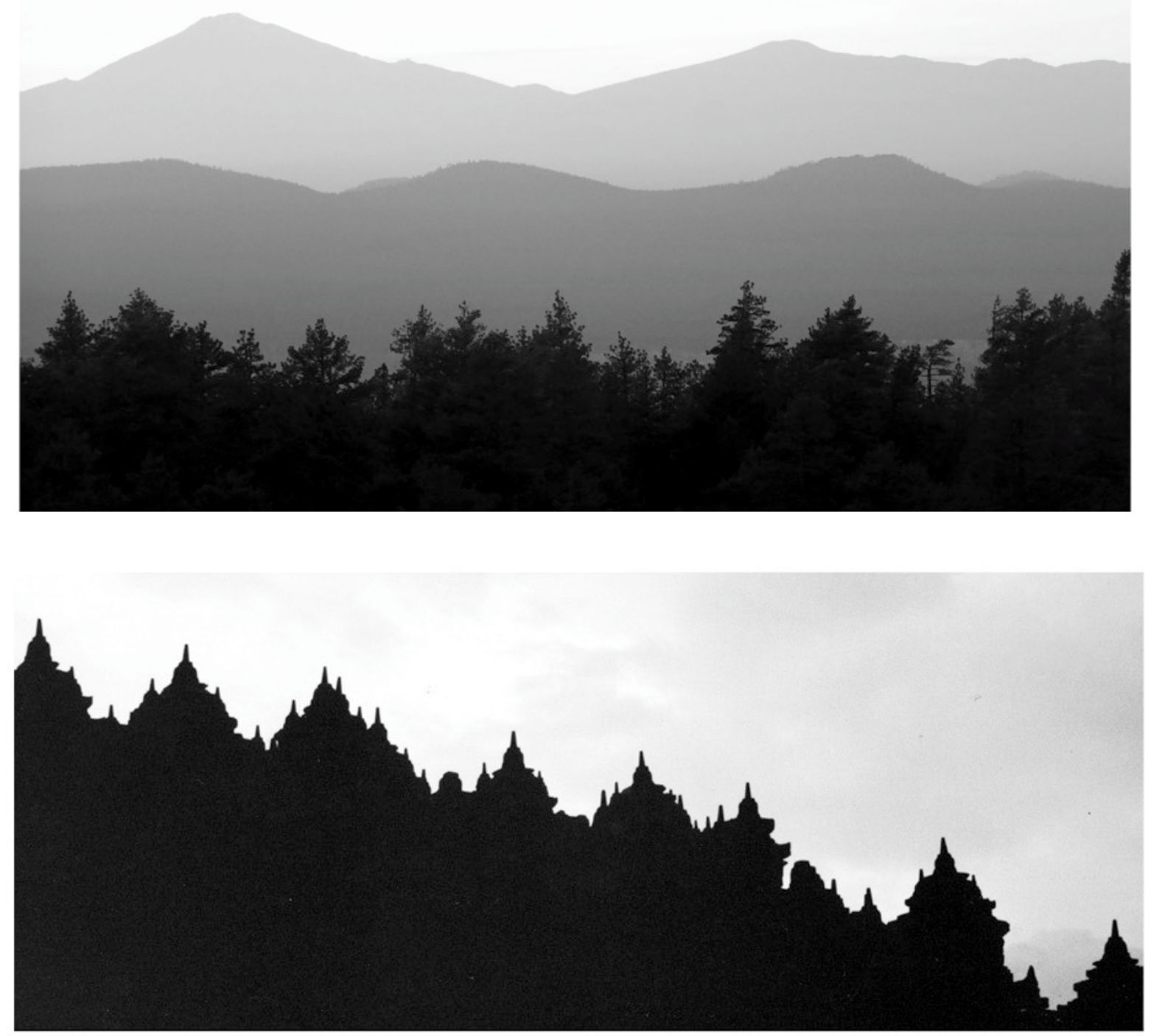

Figure 4. The top image shows several examples of natural fractal profiles with low (hill) and high (trees) $D$ values. Fine structure contributes to the fractal pattern generated by trees making it much greater than for hills, which leads to a higher $D$ value. The image below shows an example of a similar profile in buildings. Traditional architecture, such as the Borobudur Temple in Indonesia, features mid- $D$ fractal profiles. Figure and photo by R. P. Taylor.

\subsection{Aesthetic Experience}

Contemporary design, fashion, and personal preferences tend to overwhelm the suggestions of scientifically-measured reality. But art-historical explanations of urban aesthetic experience are incomplete because they lack biological foundations. At best, 
human responses are ingrained in the culture, without, however, being written down or given a scientific explanation. The cognitive neuroscience of aesthetics provides a suite of research tools and methods. That such assessments do in fact exist has been known for some time [56-59]. It is notable how useful such objective measures are in capturing the properties of individual aesthetic experience. Neuroaesthetics can help ground empirical aesthetics within the conceptual framework of cognitive neuroscience [60-63].

Psychological theories of aesthetic experience have been developed and tested with experiments that use a diverse range of methodological approaches, ranging from surveys, to computational modeling, to brain imaging. Some emphasize the importance of basic perceptual processes (e.g., [64,65]), others attention, emotion [66], social cognition [67], and their interaction [68], and yet others their typical correspondence to a substrate of brain regions and networks (see [69] for an overview).

The approach pursued here converges with Chatterjee and Vartanian's (2014) [64] notion of the interactive aesthetic triad of sensory-motor, emotion-valuation, and meaningknowledge processing [56,60]. Diagnostic tools coupled to evidence are being developed, which answer long-puzzling questions on why people prefer certain configurations, geometries, and settings. Thus, biology-based aesthetics play a central role in unconscious judgments of built and natural environments $[4-6,12,43,44]$. This is particularly true of urbanism, where architecture plays such a primal role [70-75].

Counterfactually, the broader design and planning professions have not yet adopted tools based upon biologically-based neuroaesthetics and appropriate urban scale and experience. Many professional urbanists today decouple architecture from urbanism, which the neurological evidence shows to be a mistake. Because of this major omission, the aesthetic dimension is notably lacking today in urban planning [76].

George Santayana observed that there must be in our nature a powerful tendency to observe beauty and value it, such that "No account of the principles of the mind can be at all adequate that passes over so conspicuous a faculty" [77]. But it was philosopher Edmund Burke who in 1757 made the seminal contributions to this debate by arguing that aesthetic experiences, such as those of the beautiful and the sublime, arise from the same neural processes that cause the primary driving emotions of love and fear [78]. With the opposite of pleasure being pain, philosophers such as Burke suggested that pain, fear, and terror could provoke types of aesthetic experience perhaps even more powerful than those associated with beauty and pleasure. In his Carceri, Piranesi drew what terrifying spaces might look like (Figure 5). (Note that, while colloquially the term "sublime" often means, "the highest degree or point, summit, or acme of ..." , it is used here as a technical name for the pain- or terror-based aesthetic experience, much like the distinction between "terrific" and "terrible." That was the correct usage of the terms when they were in common use: "determine at first, whether the building is to be markedly beautiful or markedly sublime". The Englishman John Ruskin understood the sublime and the beautiful to be opposites. The sublime appears to be less of a primary philosophical and art driver among French, Spanish, and Italian speakers. German language does not make this distinction as clearly, partially explaining the particular traits of German philosophy and Romanticism.) We do not wish to get into computing fractal dimensions in this paper, and only mention that Piranesi's imaginary prisons lack the ordering of a mid-range fractal that seems far more natural hence less threatening [49-55].

Following Dewey's definition of aesthetic experience as a "peak" experience, the experience of beauty would be the pleasure-based aesthetic experience that conjoins the intellectual, emotional, and sensual in a single moment. The opposite of "beautiful" would be the pain- or terror-based aesthetic experience-what art and architectural historians call the "sublime" [8,79]. Nevertheless, considering that images of the imaginary prisons of Piranesi are a standard visual reference in courses on architectural history, we are the first (to the best of our knowledge) to measure their fractal dimension. For the image in Figure 5, the box-counting method without extracting edges gives the value $D=1.9$. This relatively 
high value compared to a mid-range fractal with $D=1.3$ to 1.4 is a result of fine lines filling in the space more than seems to be optimal for our cognitive system.

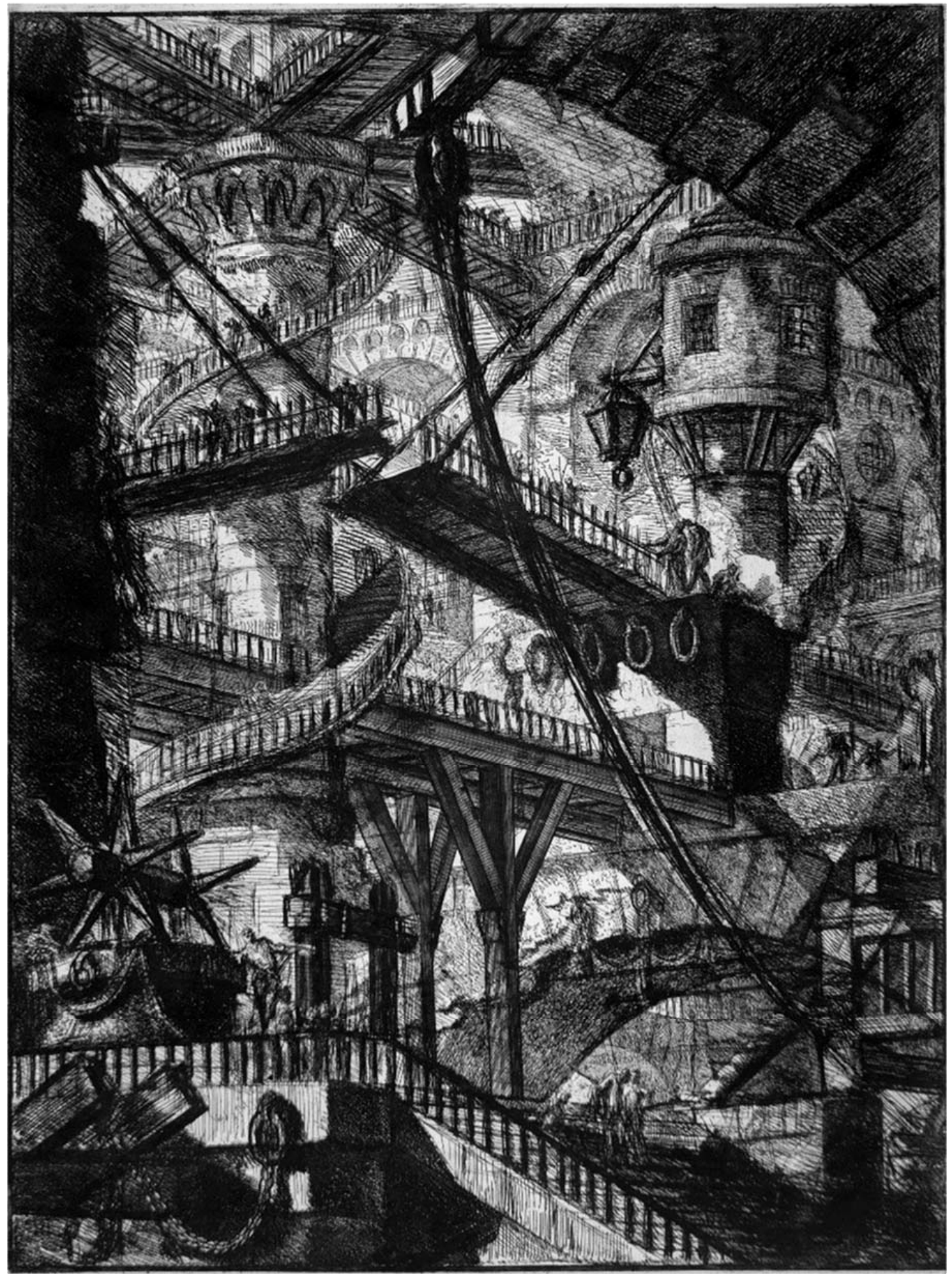

Figure 5. The Sublime, the pain-based aesthetic experience in Giovanni Battista Piranesi, Carceri d'Invenzione (Imaginary Prisons) etching plate VII, c. 1749-1761, various collections. The fractal D value of this complex and cluttered, almost incoherent image, which conforms to the definition of Sublime architecture, is large, measuring 1.9. Consequently, it is higher than the "sweet spot" of the pleasure-based aesthetic experience. Figure in the public domain. 
This concept of "peak experience" explains well the three crucial features of aesthetic experience, namely that:

1. An aesthetic experience has an evaluative dimension, in the sense that it involves the valuation of the experience of an object or scene;

2. It has a phenomenological, affective dimension, in that it is individually felt and savored; and

3. It has a semantic dimension, in that an aesthetic experience is a meaningful experience, not mere sensation [56,80].

Hundreds of studies in experimental aesthetics have demonstrated four crucial principles:

A. That aesthetic experience is individual.

B. That it is measurable by a variety of psychological and physiological markers.

C. That experiences judged as most ugly correlate with different sites of brain activity than experiences judged as most beautiful.

D. That there are aspects of beauty experiences that are indifferent to culture, gender, context, connoisseurship, or monetary value.

Furthermore, the diverging locations of brain activity related to ugliness versus beauty suggest that beauty and ugliness are not opposites-minus 5 to plus 5-but rather that the beauty scale ranges from none to very much-zero to 10, with "ugly" usually referring to something with very little beauty to it [81].

This said, the most relevant measure for our purposes here is based on the healing effect: when an object or situation is "beautiful", it is salutogenic (i.e., our body is affected positively via a physiological response); whereas when it is "sublime", it creates stress and subsequent pathology. The strong connection between beauty and pleasure in general also suggests that the beautiful is linked to approach behavior, in which we intuitively orient our eyes and bodies towards what is perceived as beautiful, an unconscious action that occurs independently of our conscious reflection.

While the experience of pleasure is associated with activation of the reward centers that are known to elicit pleasure across the board and that govern most of human hedonics and, by proxy, decision making, the experience of visual beauty is directly and overwhelmingly connected to the urban experience. A fuller understanding of the urban aesthetic experience shows that the subjective and the objective are not mutually exclusive in the urban environment, and that urban beauty is both commonly perceived and individually experienced. (A conceptual impasse is created when what is common in aesthetic experience and what is individual and subjective are conflated. While there is no doubt that mental processes are both top-down and bottom-up, there is also no doubt that an individual could not process a perception top-down without it having entered their consciousness bottom-up. Although perception and imagination activate similar brain areas, they are not the same. If they were, humans could never have collectively undertaken any activity, without which the authors and reader would never have been here to write and read this.)

One of the authors proposes that individuals register similar physiological responses to visual elements, which points to the commonality of what is perceived [8]. It also suggests that the individual information processing, which comes after we see something, is obviously subjective in that it contains unique personal memories, associations, cultural content, and judgment. This experience appears to be first governed by what is perceived and then subjectively processed by the individual's thinking, judgment, associations, and understanding [8] (p. 149).

\subsection{Visual Perception}

Perception involves the processing of sensory input that transforms low-level data points to high-level information. It extracts shapes for object recognition and reaches conclusions regarding what they constitute. The evolutionary heritage of our basic perceptual faculties ensures that our perception of objective properties and features, including form, is accurate and fast. While obviously individual - each of us has our own set of eyes, our own brain, etc.-many perceptions are nonetheless shared through our common evolution. 
We know that, within rather narrow spectrums, different things and environments produce more or less consistent effects on individuals, whether they are aware of them or not. We could not have hunted mammoths, let alone built the Internet, without some common perception [8] (p. 165). Scientific evidence indicates that the experience of beauty is triggered by two processes, one based on the objective parameters of stimuli (sensory input), and the other based on subjective social construction [82,83].

The subjective component originates in the individual's processing of their thoughts, feelings, judgments and memories, concepts, expectations, knowledge, and selective attention mechanisms that influence how those sensory inputs are processed [84]. Forty percent of nerve fibers are linked to the retina, and visuals are processed in the brain sixty thousand times faster than text is [85-87]. But while subjective processing may be present in the mind even at the start of perception, effective processing, apprehension, and ultimately conclusion regarding a new visual stimulus can only occur subsequent to initial perception [8] (p. 152, Note 28).

Given that, in the urban case, much of the experience is visual, it is possible to study the neuroaesthetic impact of what is seen as an actual useful measure of the urban experience [88]. As in any other peak experience, we can identify three phases of mental activity, here referred to as perception, apprehension, and comprehension.

- Perception occurs when the brain assembles the data of tangible, sensory input in a mainly automatic process.

- In apprehension, the individual mind grasps the perceived input and actively contemplates it based on the individual's reason, judgment, thoughts, and associations.

- Comprehension is how the mind comes to know what was pondered, generating some understanding of it or conclusion with regard to the input.

This grouping appears to correspond with the three hierarchical levels of consciousness that Zeki et al. distinguish: micro-consciousness, macro-consciousness, and the unified consciousness. The micro-vision registration of visual attributes occurs in the first 150 milliseconds after the appearance of a visual stimulus, but the difference in time between perceiving color and direction of motion is about 80 milliseconds, a huge difference considering that a nervous impulse traveling between cells takes only about 0.5 to 1 millisecond. Since it has also been demonstrated for the level of the macro-consciousnesses that binding between attributes takes longer than binding within them, neuroscientists postulate that the binding of multiple macro-consciousnesses into a unified consciousness would take longer still $[89,90]$.

\section{The Temporal Sequence of the First Milliseconds of Visual Stimulus Processing 4.1. Three Stages for Perception Cycles}

This section presents data from previous experiments that illuminate the time sequence of cognitive and perceptual processing of visual information. We summarize here those findings to guide the interpretation of human responses to urban visual environments. Our objective is to reveal how the rhythm of pedestrian ambulatory movement is strongly influenced by the geometry of the environment, independently of the navigational goal fixed in the conscious memory.

Psychophysical experiments demonstrate that different cardinal attributes of vision are neither perceived nor processed simultaneously in time. A detailed description of the specific brain processing sequence reveals the intimate relation between visual fractals, and the evolved fractal mechanisms built into our body. Primary sources for this section include [91-100].

Pre-processing stage

Each eye has 126 million photoreceptors and these reduce to only 1 million neurons in the optic nerve connecting to the brain. Thus, considerable data compression occurs at the pixel detection stage in the retina. Along with compression, image enhancement also occurs in the retina. Given that the retinal neurons have fractal shapes, and also that fractal compression techniques are exploited in commercial computing, it is interesting to 
speculate that this initial detection stage has evolved to efficiently compress and enhance fractal patterns.

Stage one: Detection-0-40 ms

In the constant stream of visual information, detection occurs about 5-10 ms after the appearance of the visual stimulus. At about $28-40 \mathrm{~ms}$, an object's form, orientation, and directional motion reach the visual brain, launching the perception of orientation, faces, and objects. The most basic visual hue and luminance contrast computations are reflected in the earliest parts of the perception sequence, with the visual system tending to use luminance contrast to continually update representations of scene structure, enabling the encoding of discrete events based on location.

Stage two: Perception (pattern detection) -10-150 ms

40-80 ms: By $35 \mathrm{~ms}$, signals are potent enough to elicit and sustain a simple and conscious, if crude, experience of moving visual stimuli. Then, some $80 \mathrm{~ms}$ after initial perception, human subjects perceive different visual attributes of the same object asynchronously, "binding" the color of the object initially perceived to its perceived motion direction, with lingering representations of hue useful in grouping and remembering visual information.

100-150 ms: Luminance contrast peaks at 100-110 ms after stimulus onset, and hue accuracy at 120-125 ms, at which point generalization occurs, attributed to differences in task performance or imagery and comparable to decoding for shape-independent object category. Significantly, luminance contrast is decoded less reliably for orange/blue (yellow/blue), "daylight" hues, than luminance signals associated with pink/green (red/green), colors associated with the "anti-daylight" locus. This finding suggests that the neural representation is primarily adapted to natural lighting conditions, which should not be surprising. Temporal neural processing and perception integration aligned to eye movements seems to also follow $150 \mathrm{~ms}$ after stimulus onset.

It is suggested that scenic information is processed in the visual cortex in a system of virtual "pathways" [101,102], distributed through evolution to directly match the fractal scales that dominate the environment, and in a number relative to the number of objects of that size within the scene. It has also been proposed that fractal processing makes use of fractal images stored in our memories by simultaneously integrating current perceptual information with long-term memory [103], suggesting that the brain calls on fractal memories as part of visual processing [104].

Environmental psychologists know that our surroundings influence not only the way we think but also the way we feel. They recognize that experience comes from the individual's mind scanning the perceived landscape and identifying patterns with specific characteristics, as the urban experience exemplifies. A significant aspect of aesthetic perception is based on properties that mirror the typical environments of human evolution. These have a specific range of complexity, scaling iteration, and so on. The built environments that accurately mirror such properties are perceived as safe, interesting, comfortable, and beautiful $[3,6,8,12,43,54]$.

The conclusion that the eye searches through the scenery to confirm its fractal character is reached by considering that the mammalian visual system evolved in a fractal natural environment, hence is optimized for it [105]. This is shown in Figure 6, below (following the analysis of Reference [19], which does focus on the subject of the figure). Since mammalian peripheral vision lacks the resolution to detect fine-scale patterns in regions further away from the gaze's focus, the gaze moves to enable the eye's fovea to sample the fine patterns at many different locations. The eye then experiences the full distribution of coarse and fine-scale patterns necessary for confirming the scene's fractality. 


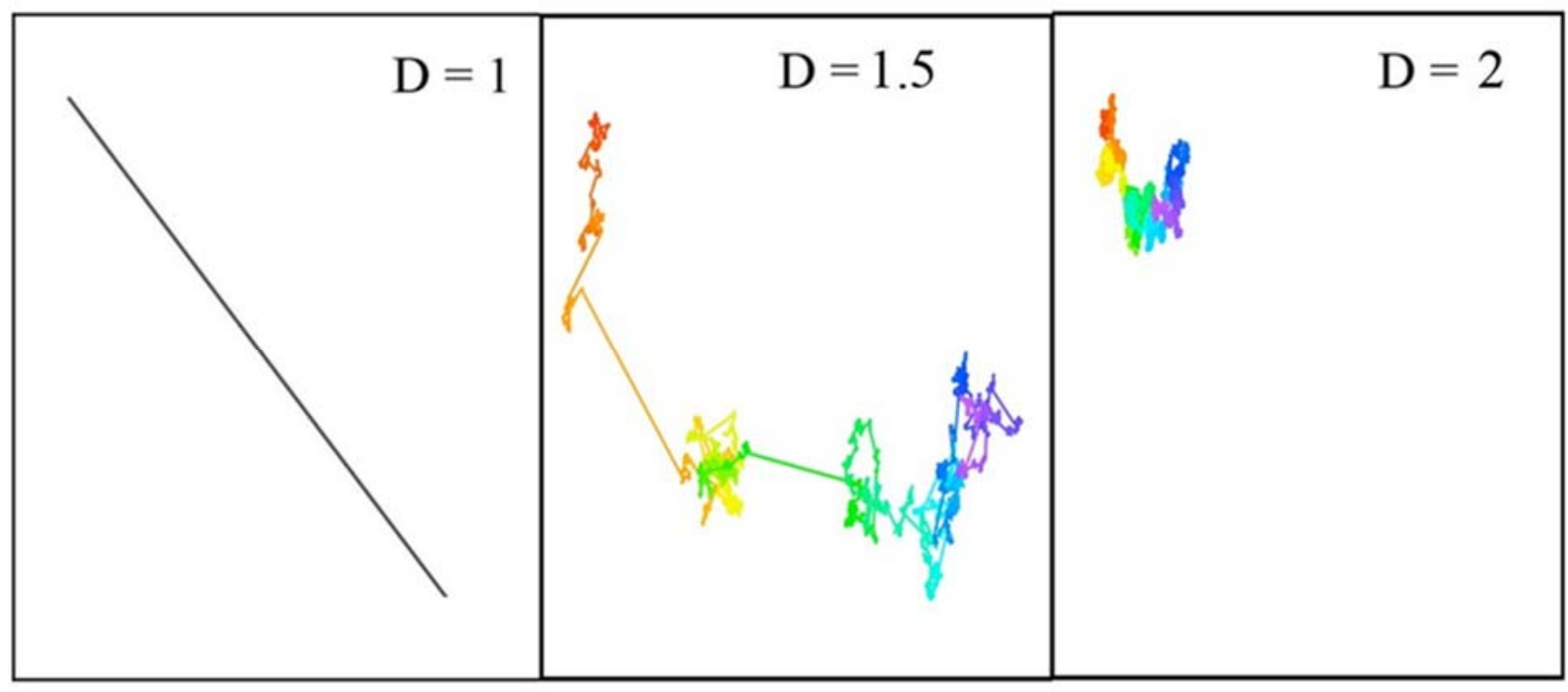

Figure 6. Fractal trajectories are adopted by foraging animals and for visual searches: The fractal trajectory (middle) is optimal for searches when compared to straight trajectories (left) and random trajectories (right). Figure by R. P. Taylor.

The answer to why the eye follows a fractal trajectory during this search can be found in the foraging behavior of animals [106]. That is, eye-scanning movement shares the model for the body's physical movement. Much as animals benefit from the mathematical efficiency of multi-scaled, semi-random fractal searches when exploring their natural terrains, the eye's search for meaningful visual information appears to exploit the same patterns. Pupil dilation also varies in a fractal manner as the eye moves over the fractal images, suggesting further refinements in the search mechanism [23].

Thus, people are hardwired to respond to specific forms of fractals found in nature. In parallel, stress reduction is physiologically triggered when the eye-scanning fractal pattern matches the fractal image being viewed. Experiments have determined that fractals half-way between a line $(D=1)$ and a full area $(D=2)$, as characterized by their fractal dimension $D$, give the most pleasure. Thus, our eyes scan in a fractal pattern of $D=1.3$ to $D=1.5$, seeking fractals with satisfying dimensionality at around $D=1.3-D=1.5$. Upon finding them, the brain releases endorphins, automatically relaxing the person and greatly reducing stress levels [39]. Experiencing beauty releases a powerful wave of neurotransmitting epinephrine, dopamine, phenyl ethylamine, and endorphins [107].

Metrics additional to the fractal $D$ dimension value formerly proposed, such as statistical fractals, can be introduced as criteria for measuring an environment. There is the possibility of building a synthetic metric based on them; nevertheless, that is best left to another paper.

Employing quantitative EEG techniques to provide quantitative analysis of brain activity indicates that peaks in alpha waves are associated with wakefully relaxed states, while peaks in beta waves indicate heightened attention [26,51]. Strikingly, fractals induce large changes in both relaxation and arousal responses, indicating their unique role in the visual system. Preliminary studies employing fMRI show that the parahippocampal region of the brain is being utilized, indicating the involvement of memory retrieval and scene recognition; together with the default mode network, a large brain network associated with wakefully restful activities, which features in modern versions of attention restoration theory [108].

Stage three: Identification and initiation of a new perception cycle-150-200 ms

Considering eye movements in more detail, we find that within our broader field of vision, the only sharp and fully colored visual information comes from the fovea, the size 
of which corresponds approximately to the size of your thumbnail held up with your arm fully extended (i.e., only $1^{\circ}$ to $2^{\circ}$ of the visual field). To gain the same high-resolution visual for the entire field of vision, we need to align our fovea with several places in our environment, i.e., we need to move our eyes.

Humans hover their eyes primarily with one type of voluntary, quick eye movement called saccades. Saccades sequentially move the center of vision, the fovea, to different spaces in the visual environment. It takes about $150-200 \mathrm{~ms}$ to initiate a saccade and the duration of each one varies depending on the distance the eye travels. People typically make one long saccade followed by several smaller ones when exploring their visual surroundings.

Eye-motion studies following the observer's gaze when they look at visual images confirm that the eye follows long saccade trajectories when jumping between points of interest and smaller micro-saccades during dwell periods [19]. Significantly, examination reveals that saccade trajectories traced out fractal search patterns, regardless of the geometry of the image, and the neurological conditions of the participants, suggesting that the fractal motion is intrinsic to eye-motion and is not influenced by higher level processing in the visual system [22].

The location and duration of fixations is recognized as a powerful research tool and has been used for decades by psychologists and neuroscientists to investigate what parts of an image people pay attention to (fixation location) and how much information they are sampling from there (fixation duration). We have gained great insights into how people process faces, for example, by recording which facial features are looked at for how long.

By around 150-160 ms, salient items in the visual field have been detected and identified. High-level category representations are activated at around $150 \mathrm{~ms}$, and robust peak responses for stimulation with faces, houses, oriented lines and colors occur at about 150-170 ms. High-level cognition on decoding color with object perception peaks at $200 \mathrm{~ms}$.

While color-related representations distinctly precede shape-related representations both in the processing hierarchy and in time, perceived object similarity in relation to shape, function, color and background apparently links object dimension and representations in the visual cortex within $200 \mathrm{~ms}$ of stimulus onset. In all this, neural activity appears to group or chunk information in "perceptual echoes" across multiple regularly recurring cycles at around $100 \mathrm{~ms}$, with integration cycles occurring at $200 \mathrm{~ms}$ for repeated natural images.

An identifiable perception shift at $150-200 \mathrm{~ms}$ possibly indicates that the rules regulating visual brain processes during the first $100 \mathrm{~ms}$ may be unique to that time frame and perhaps even separate from those governing subsequent cerebral operations. Indeed, visual consciousness factors such as attention, memory, and decision-making seem to emerge between 180 and $230 \mathrm{~ms}$ post-stimulus onset.

\subsection{Biophilic Review}

A review of the biophilic factors helps to further illuminate the urban experience. On the one hand, very fast visual searches connect with the fractal environment, and then the brain condenses that information using fractal image compression. In parallel, geometrical symmetries in the environment compress the available information independently of fractal compression. The presence of multiple fractals and nested symmetries guarantees that environmental information does not exceed the brain's capacity to process it. Biophilic design tries to include geometrical qualities that are known to be responsible for the biophilic effect [2,109]:

1. Sunlight: preferably from several directions.

2. Color: variety and combinations of hues.

3. Gravity: balance and equilibrium about the vertical axis.

4. Fractals: things occurring on nested scales.

5. Curves: on small, medium, and large scales.

6. Detail: meant to attract the eye. 
7. Water: to be both heard and seen.

8. Life: living plants, animals, and other people.

9. Representations-of-nature: naturalistic ornament, realistic paintings, reliefs, and figurative sculptures-including face-like structures.

10. Organized-complexity: intricate yet coherent designs-and extends to symmetries of abstract face-like structures.

These factors are found implemented in the most attractive parts of the built environment, whether historical or recent. As the present paper tries to demonstrate, the unconscious attractiveness is explained because evolved positive sensory mechanisms are being stimulated. While people react to the ensemble sensation with pleasure, using emotional but imprecise words like "charm", it is in fact their body that is unconsciously generating a positive neurological and hormonal signal. At the same time, most urban and architectural designers today that heed Modernist dogma actually seek out and eliminate such pleasurable sensory reactions from their projects - in order to attain severe, stylistically minimalist appearances.

\subsection{Perception Cycles}

When looking at a relatively static scene, the eye rests on a given location for approximately 150 to $300 \mathrm{~ms}$ before the next saccade occurs, resulting in about 2-4 eye movements per second. The resting time between saccades is called fixation time and the current consensus is that we take in most (if not all) of the visual information during fixations. Thus, under most circumstances, eye movements and human gaze behavior can be described as a sequence of saccades and fixations [110].

Both Magnetoencephalography (MEG) and behavioral measures indicate that "emotion measures" come into play after sequential segregation and integration processing in repeated cycles of 200 to 300 or $350 \mathrm{~ms}$ from stimulus or eye fixation onset, and that post-stimulus neural signals rhythmically parallel ongoing brain oscillations, with spike rates linked to both ongoing and saccade-induced oscillations.

For urban perception, high temporal resolution may be critical for encoding walkinggait stimuli as well as supporting rapid scene variability. Eye movements actively sample the environment, and the close coordination between motor and sensory systems explains the drastic sensory changes associated with each saccade, which prepare the visual system for a new spatiotemporal pattern of input with each new fixation in frequencies of around 200-300 or $350 \mathrm{~ms}$. During walking, the stimulus is continuously present and would be discretely sampled by saccadic eye movements at that rate, with the visual system preserving separate retinal images across saccades as a part of saccadic remapping.

\subsection{Bottom-Up and Top-Down Processing}

Over the past few decades, the separation between so-called "bottom-up" and "topdown" processes has blurred considerably. Even though the distinction seems intuitive, it is far from obvious [111-114]. Nonetheless, a broad distinction can be made in the context of perception. Bottom-up processes are driven by the physical properties of the perceived object, and they are fast. In contrast, top-down processes are driven by the observer's conscious goals, state of mind and her knowledge. Top-down processes are usually considered slow and deliberate.

Because top-down processes by and large depend on knowledge about one's current environment, it is reasonable to assume that the majority of top-down processing occurs only after basic visual processing, i.e., object recognition, has taken place after about $150 \mathrm{~ms}$ for faces [115] and up to $350 \mathrm{~ms}$ for generic objects. Importantly, top-down processing not only influences the evaluation of the already recognized object, it also influences subsequent bottom-up processing and, even before that, from where people next decide to sample new information. For instance, once people have understood that they are looking at an image of a particular room, e.g., a kitchen, they become highly efficient in finding objects within that room, e.g., a loaf of bread [116]. 
This latter point is of particular interest to our case since it also has implications for how people navigate the built environment. If people can quickly and accurately identify the kind of environment they are in, they will be able to navigate their eyes and bodies efficiently within that environment. While definitely not needing to be identical, the relevant urban objects-door, sign, window, stairs-need to follow common characteristic structures to enable quick identification, and hence successful and stress-free navigation and interaction in urban spaces. The fact that much of our ancient evolutionary environment follows multiple fractal patterns and that even our eyes' movements seem to have been adapted to follow these regularities, suggests multiple fractal patterns as one of the most fundamental, expected structural components of our environments.

\subsection{Ambulatory Motion and Brain Processing}

Much of the above exposition synthesizes experimental results by others, and ties it to the context of perceiving urban space. The contribution of the present work is towards a new understanding of how unconscious processing of environmental information influences the act of walking. This, in turn, determines where we go, or whether forcing us to follow a predetermined trajectory (because we have to advance in that particular direction) is either pleasurable or generates stress.

The alignment of processing to new fixations, either by extending ongoing saccades or by creating new cycles ex novo, influences processing for less than $1 \mathrm{~s}$. This may be due to individual intentions to make further saccades and micro-saccades, or to resetting the fluctuation to keep step with neural oscillators. These measurements also correlate to Moti Salti's four phases of post-stimulus processing, identified as being 0-115 ms, 115-165 ms, 160-275 ms, and 270-800 ms [94].

Generally speaking, in the pedestrian urban experience, there is a correlation between the rhythms of ambulatory motion and the brain processing of information from the environment. A predominant, diminishing cycle of approximately $150 \mathrm{~ms}$ repeats, for one or two cycles, during which the brain recognizes and integrates patterns approximately every 150-450 ms. Depending on the exact task, after about $300 \mathrm{~ms}$ higher-level processing is activated-or not, when it received no fractal reinforcement in a subsequent cycle. Walking 60 feet, as indicated in Figure 7, the brain undergoes 90 to 120 perception cycles.

Summarizing the above technical discussion, informational signals from the environment influence the body into unconsciously deciding on optimal direction and speed of ambulation. A conscious top-down decision, such as the need to go in a particular direction or towards a specified goal, competes in a sequence of choices from among which the brain selects. Multiple unconscious signals act on very short time scales, as documented above, whereas any conscious decision is long-term and has to be continuously reinforced 6 to 7 times every second if it conflicts with those unconscious signals. This reinforcement mechanism is an imposition that generates stress.

Significantly, it is not inaccurate to identify this mechanism as an engine for stress generation. Since the time for one walking step is on the order of under one second (though highly variable), then the rhythm of pedestrian ambulatory movement is strongly influenced by the geometry of the environment, independently of the goal fixed in the conscious memory. This finding totally revises the standard understanding of a "walkable urban environment", which delineates streets and urban spaces in a plan's abstract geometry while ignoring unconscious human experience and emotions. 


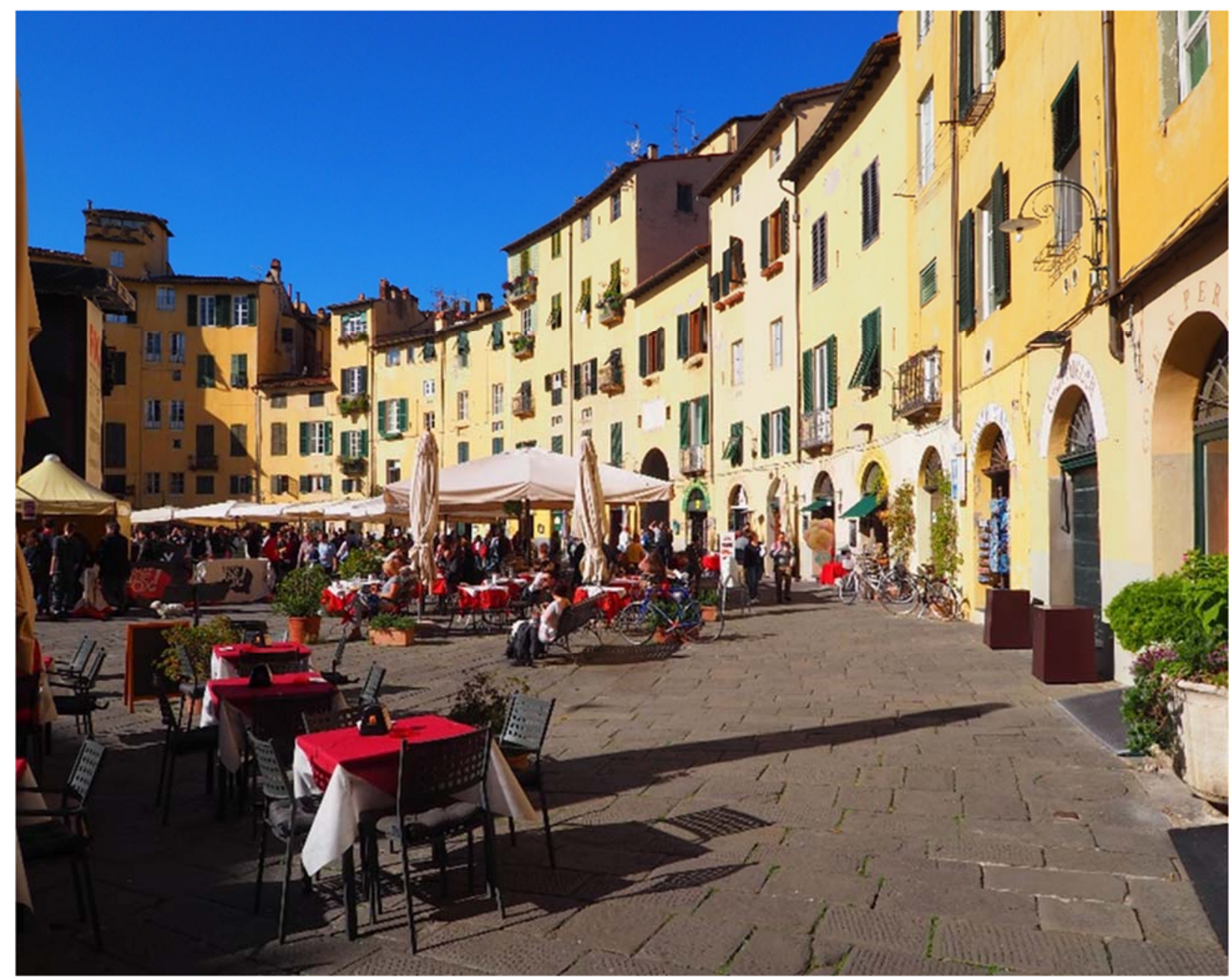

Figure 7. Walking 60 feet from the red-topped table in the foreground to the pavilion tent in the center of the picture, the brain undergoes 90 to 120 scanning cycles. The Piazza dell'Anfiteatro in Lucca, Italy. Photo N. H. Buras.

\section{Discussion: Urban form and User Experience}

\subsection{The Importance of Fractal Patterns}

Fractals are one of the most prominent statistical regularities we encounter in our natural visual environment. To efficiently process fractal patterns, it is highly likely that our visual system has developed along multiple temporal scales from ontogeny to phylogeny. This ease of processing and expected ubiquitousness of fractal patterns both provide excellent reasons for their subjective appeal. In fact, eye-scanning experiments independently confirm that our unconscious visual attention is drawn to fractal patterns, whereas blank or monotonously repetitive (non-fractal) surfaces are ignored.

When we walk down the street, we not only constantly absorb visual sensory information, but we also automatically process and evaluate it. One of the most fundamental evaluations of sensory information is in terms of its aesthetic experience, its pleasantness or beauty. Scientific evidence points to the contribution of multiple fractal scaling, making it possible to pinpoint the geometrical qualities that induce the best experience $[1,2]$. People have known about the elements of biophilic design for millennia without calling them as such. In fact, the design techniques for making the best human environments (i.e., those that are measurably good for our emotional health) have been in practice for 5000 years, minus the last hundred.

The utility of this understanding is exemplified by the case study proposal for refacing the British embassy in Washington D.C. (Figure 8). While the results of this paper apply to 
any design idiom that accommodates biophilia, fractal fluency, and nested symmetries, they are inherent in the architecturally literate classical method and its design styles. Putting a real roof on the building and re-facing the embassy's concrete eggcrate with a 12-inch-thick stone Georgian façade will not only elevate the building to better reflect British culture, but it also improves daylighting through higher ceilings, resists the ravages of weather through solid walls, and improves the climatic and energy performance of the windows by using shutters and drapes.
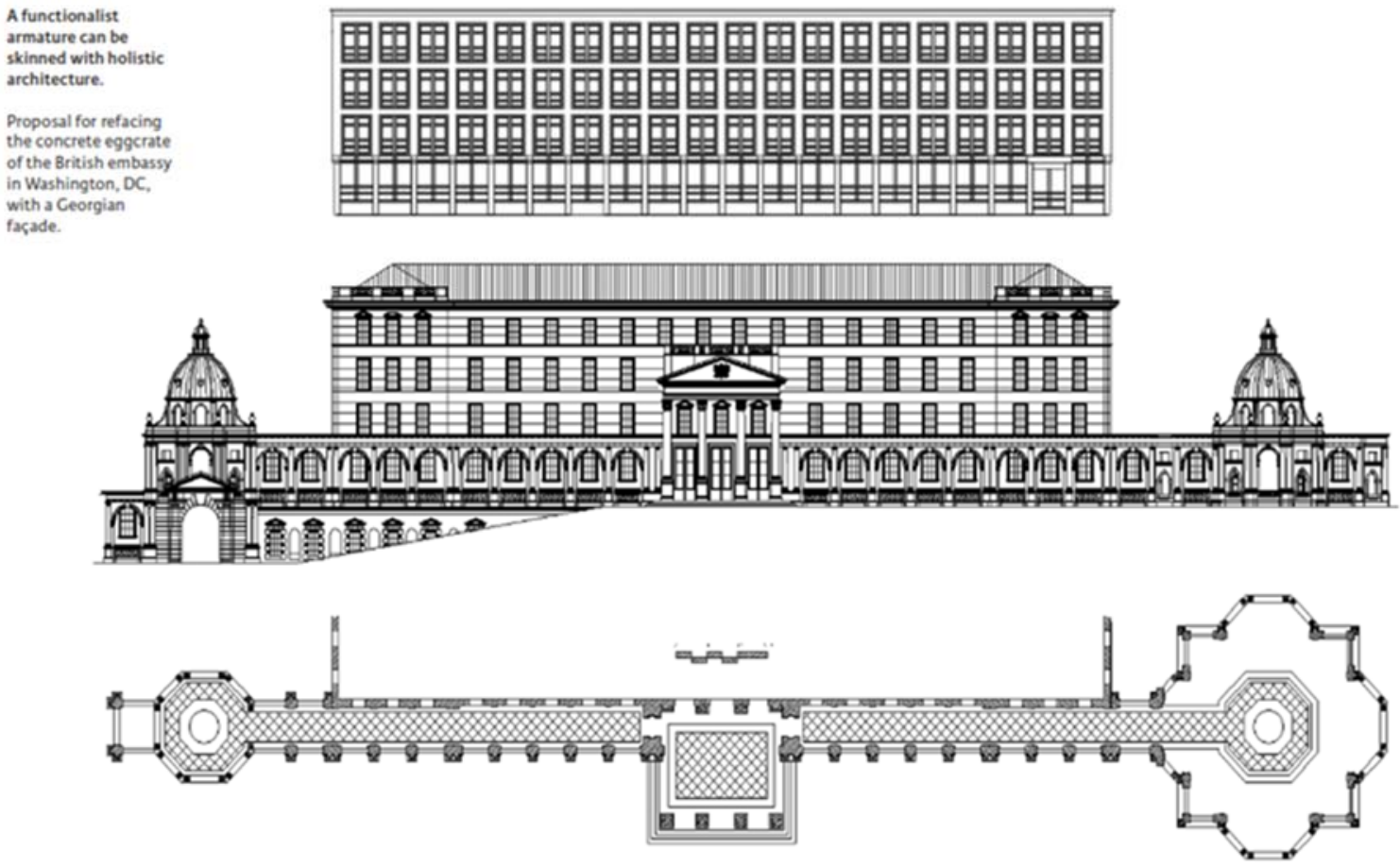

Figure 8. A functionalist concrete eggcrate design can be completed with biophilic architecture. Proposal for facing with a Georgian façade the utilitarian British embassy structure in Washington, DC. Figure by N. H. Buras, 2021.

But with the express goal of achieving notoriety and novelty, 20th century architectural ideology is leading 21st century planners and architects to eliminate the very properties that elicit human well-being in cities. Following decades of confused and erring design practice, professionals continue to prescribe anti-fractal typologies in order to satisfy requirements for "abstraction" and formal "purity". Those designs mimic machine parts in their forms and-ambiguously and self-referentially_seek to be "of their time". By using them, architects and urbanists forcefully shape our cities today with sleek, "minimalist" geometry, abrupt, large, smooth surfaces, and blank, shiny glass walls.

Contradicting the fractal structures and patterns with which we are hardwired to experience environments, "cool" spaces and buildings neurologically alienate us and induce stress [8] (Chapter 6, pp. 160-161). For the first time, the research points to the fact that design for humans must focus on user experience and not on designer creativity, ideological notions of "being of our time", or aesthetic notions of so-called "functionalism" [117].

\subsection{Walking Down a Street}

Phenomenology and Evidence-Based Design validate that architecture and urbanism strongly shape the human experience. They confirm that buildings and urban spaces impact us whether we are conscious of their detailed geometries or not [3,118-122]. On a very fundamental level, we are attracted to environments that are aesthetically pleasing and therefore invite their viewers to approach them. Manual motor movement experiments (reaching), showed that movements toward a thing that seemed more attractive were 
faster and more precise than those to unpleasant or undesirable goals, which resulted in slower, less precise movements, even extended in "avoidance detours." Current research even identifies differences in running motion when people are exposed to aesthetic environments [123-125].

Extrapolating from such experiments, we gain a sense of urban movement encouraged positively by the attractiveness of its environment, rather than being slowed down, made stressful, or hampered by the nature of a less attractive built environment or one more challenging to process [126]. As we step forward along a street such as Las Ramblas in Barcelona, Spain (Figure 9), the sequence of perceptual signals influences the motor function of taking the next step because of the perceived attractiveness of the goal, and reduction in anxiety while proceeding down the street which would consume energy and take it away from navigation.

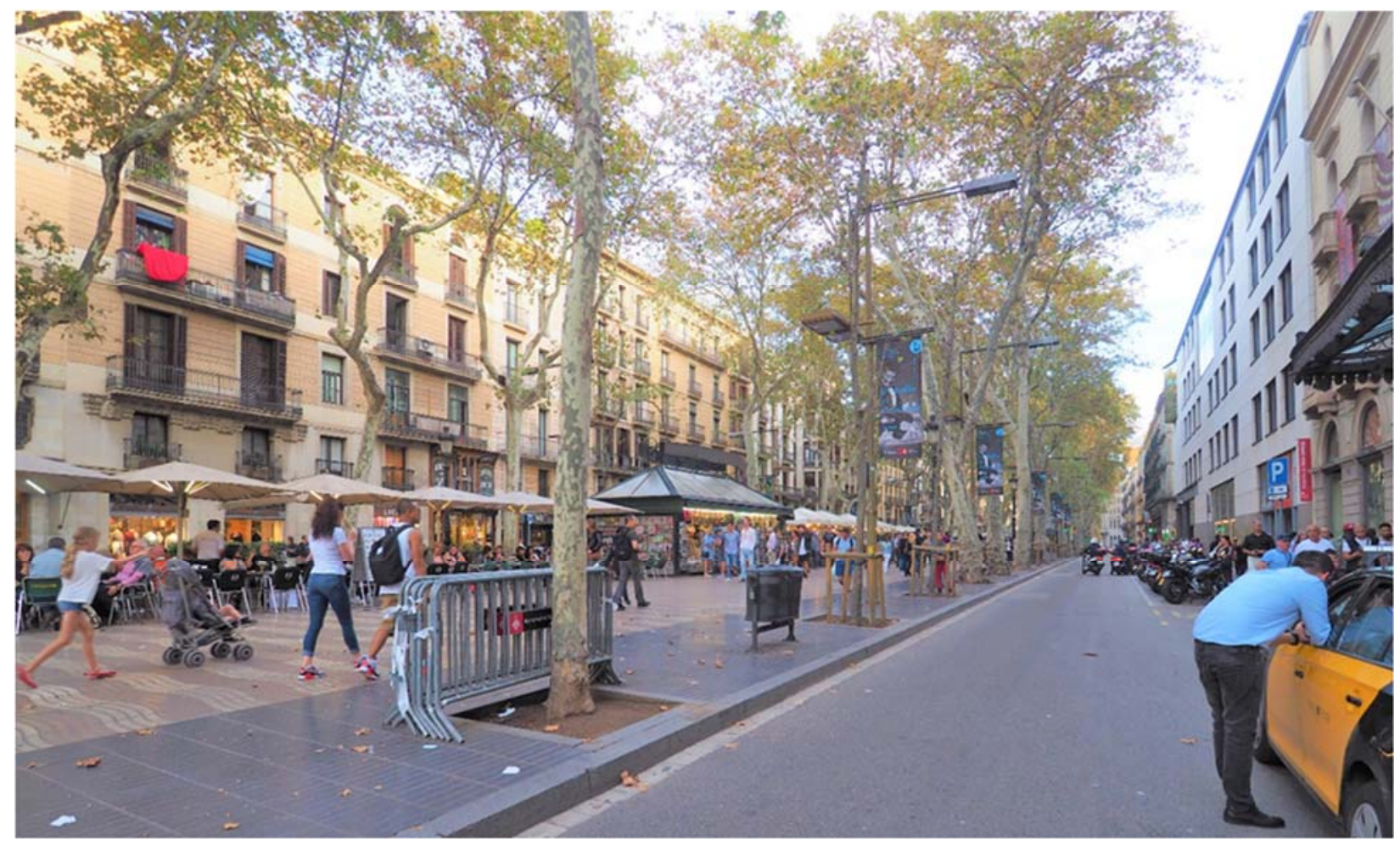

Figure 9. Las Ramblas, Barcelona. Photo by N. H. Buras, 2017.

Walking down a street, an individual may experience (i) the attractiveness of positive aesthetic experience; or (ii) the avoidance caused by a negative, fear-based aesthetic experience, causing them to retreat or detour sideways; or (iii) a third option, where despite the anxiety, one is drawn to continue in the direction they were headed by forcing themselves to apply will power to proceed into an ugly, if not stress-inducing environment that they might intuitively avoid. Statistically, this third instance overwhelmingly describes today's user experience. We move towards and enter a specific building because we have a task to accomplish there, otherwise we would not be attracted to go near it (if faceless and uninteresting); or would actively stay away (if menacing and ominous).

\subsection{Fractals in Navigation and Wayfinding}

Everyone by now has witnessed, at least anecdotally, how in cities ugly streets that more readily connect two points - and even include bike lanes-are underused because of the poor visual environment that they offer people. People tend to prefer using the prettier traditional side streets even when they might be completely congested, rather than 
the objectively more "accessible," "objectively better," "functional" streets, the ugliness of which is so off-putting that people feel less safe on them.

Intriguingly, as was discussed earlier, people's ability to navigate improves in fractal scenery because information is focused and unique. This feature stands in contrast to Modernist streets, where there are no eye- or body-fixation points for navigation, such as found in an environment that is naturally structured.

In brief, naturally structured environments are easier for us to process. If the environment is so structured that it is conducive to how we naturally process the world, there is less strain on the bodily system. There is reduced stress as resources are freed up to the task of navigation-and to connecting with other people-which is the purpose of urbanism in the first place.

Visual attractiveness reinforces the forward ambulatory movement and fosters walkability. That makes walkability all about the environment being attractive, not about what you can presumably find in it in the way of services or institutions [8] (p. 148). The process of navigating in an environment is totally dependent upon the information content of those surroundings. Therefore, the ease of information processing directly affects decisions about our movement. As discussed earlier, recent experiments have shown that people navigate better in appropriate multiple fractals scenery.

\subsection{Façade Fractals and Urban Plan Fractals}

A façade's aesthetic attractiveness depends upon visual factors such as obvious fractal structure coupled with nested symmetries. This description is style-independent, yet all buildings satisfying these essential requirements do share a somewhat "old-fashioned" look. Such a multisensory characteristic is however misunderstood by the design profession, which judges traditional design as not being "innovative" enough. In reality, the impression of "familiarity" is an unambiguous signal to the neural system that a façade indeed mimics our ancestral environment-incorporating biophilia, fractal fluency, and nested symmetries - in its informational structure. By contrast, extreme design novelty, achieved through eliminating "familiar" sensations of feedback, only succeeds in erasing evolutionarily crucial visual cues.

Although one rarely, if ever, perceives an urban plan as part of the walking experience, on the urban scale, fractal structure tends to develop naturally in settlements, reflecting that their growth shares many essential characteristics with natural growth. Many original building footprints, and portions of street grids survive as a community upgrades its fabric, using increasingly durable materials without changing its plan. Much-loved historical urban regions have this feature. A fractal foraging distribution of uses and sizes, in both the street network and in the building footprints, is characteristic of urban fabric produced by organic growth, even in traditionally planned cities with grid plans which prove often to be neither monotonous nor placeless $[8,127]$.

While the fractal strategy would have allowed our ancestors to identify the very distinct animal forms within fractal scenery-and thus promote their survival - the eye does not find any fractal character or safe scenery in a smooth Euclidean street, which is perceived as featureless. Fractals found in nature are most often statistical fractals, not exact fractals; and perhaps most significantly, a pleasing and calming fractal landscape consists of more than one type of fractal seen at a time.

In contrast to the single fractals of perceived infinite oceans or endless sand dunes under a clear sky and blazing sun, human-sustaining scenery might typically contain trees, clouds, mountains, rocks, plants, water, and sky, as found in the landscape of humankind's emergence, the African savannah. To be salubrious, the fractality of the built environment would be both statistical and multiple-fractal. And it should be composed of a graspable complexity. Multiple fractal visual detail pleases the brain when it is found in the uniquely human forms and geometrical interrelationships of man-made places. The sense of biologically-based beauty thus engendered arguably reflects the embodied cognition of the aesthetics of humankind's evolutionary landscape [8] (Chapter 6, pp. 152-158). 
Any positive interaction between a person and the surrounding environment depends upon very specific geometrical features. Just having a good urban plan that satisfies multiple criteria does not necessarily make a good place; neither does the mere presence of a single fractal pattern generate a pleasant aesthetic experience. Like in nature, the requirement for statistical fractals found in the built environment is that they must be multiple, and their dimensionalities all in the $D=1.3$ to $D=1.4$ range of intermediate fractal dimensions. Moreover, independently of the fractal scaling, their overall shapes and subcomponents themselves need to be coherent, based on the principles of architectural literacy, and visual coherence achieved through nested symmetries and biophilia.

While architectural proportion is most commonly interpreted by architects and critics in a distinct and limited manner to denote the ratio between the height and base of a rectangle, this common interpretation is merely a hint as to the fuller nature of the classical proportioning methods. The multiple proportional systems that generate the Classical Orders are statistical fractals [8] (Chapter 6, p. 156).

The statistical fractals that make up the architectural experience in fact measure relative dimensions among multiple perceived edges. These proportions include 1:1, "equality" (symmetry), 1: $\phi$ "differentiation" (little-big; $\phi=1.618), 1: \phi^{2}$ "punctuation" (tip of the leaf, the fingernail to the finger, tip of the nose), and several others mentioned in Buras [8]. A total of six and possibly seven relevant statistical fractal proportional systems operate in the traditional built environment simultaneously, whereas sometimes none appear in Modernist design [128]. Figure 10 illustrates two of them, "differentiation" and "punctuation."

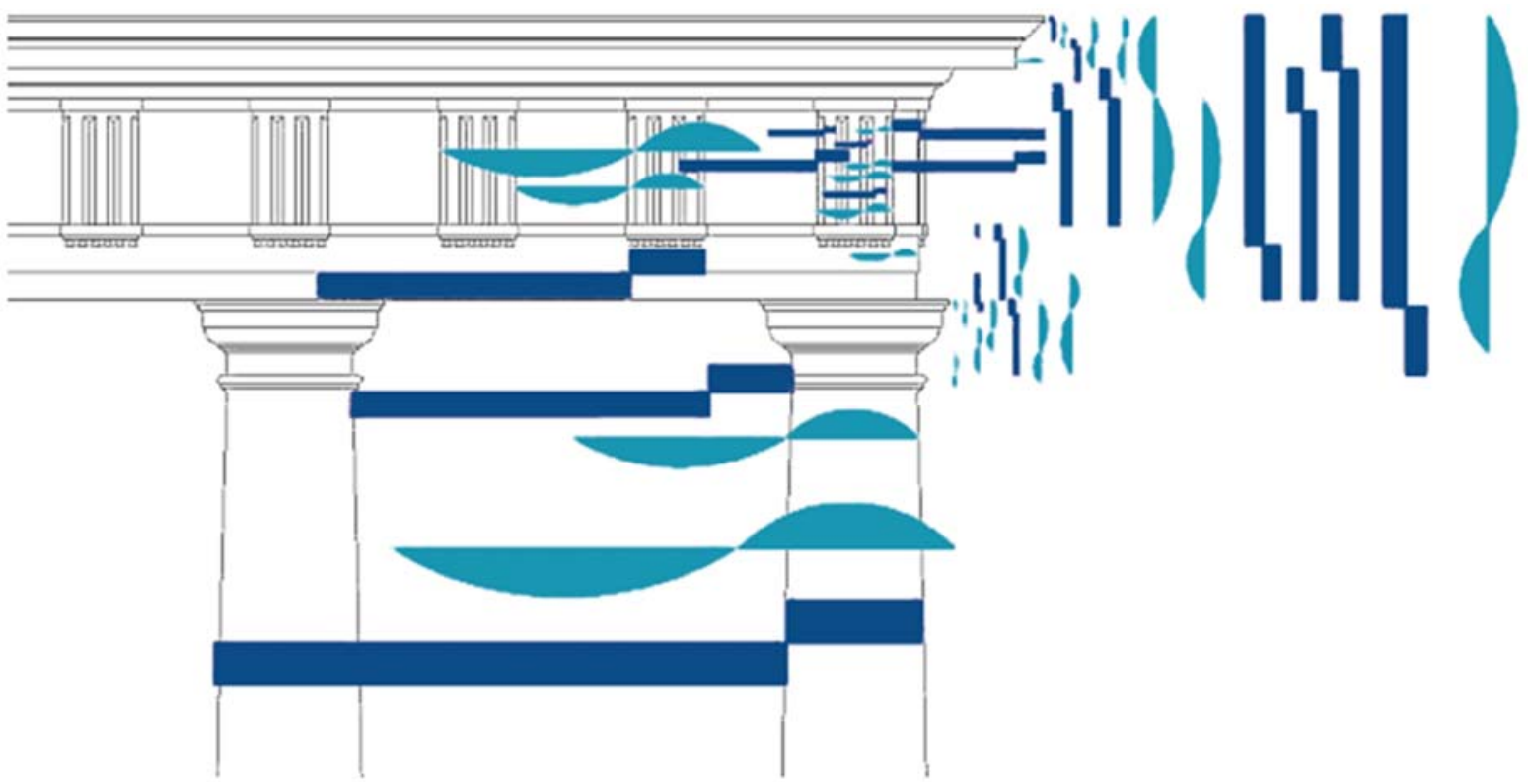

Figure 10. A human seeing a classical building recognizes its identity as readily as that of a tree-and is similarly satisfied by the multiple fractals it finds in the architecture. The multiple systems of proportion of the Greek Orders are statistical fractals. Differentiation, "Little-from-Big," is noted by the curved arcs. Punctuation is noted by the bars. Symmetry is obvious and is not diagrammed. Figure by Nir Buras.

Notably, the geometry of beautiful cities is very specific, and follows these neurophysiological variables. Among the greatest pleasures in life is wandering around their lovely streets, commonly notable for their traditional architectures. The relationships of the immune, nervous, and endocrine systems, and of emotions and the body to aesthetic experience compel us to conclude that traditional and classical environments contribute directly to human well-being [8] (Chapter 6, p. 158), [129]. 
Traditional Western architecture precisely fits the human fractal neuroaesthetic requirements [130]. In traditional buildings, the basic proportional relationships between the elements and shapes that make up contours and details recur in multiple simultaneous proportional systems and at five different scales in every part of its design. This is a straightforward result from fractal fluency, since a fractal will incorporate several levels of scale into itself. When working with buildings (say, up to six stories), the number of well-defined scales from the overall size down to the architectural detail is somewhere around seven if we use the most common traditional scaling factor of approximately 3 [131].

\section{Conclusions}

A beautiful built environment can change people's lives for the better. We based the judgment of "beauty" in built structures on neurophysiological criteria and measurements, thus circumventing old and inconclusive debates in aesthetics and architectural history. The evidence presented here collects and synthesizes many scientific experiments performed relatively recently. The lack of empirical evidence in some of the mentioned research is certainly a limitation, which needs to be addressed. Hoping that the present model attracts the design profession's attention, then we will have established a direction in how to fill in this knowledge gap through future research.

Our largely subconscious memories of cities are formed viscerally, at the physical scale of our bodies, mostly on the pedestrian level. Beauty is a leading cause for urban emotional attachment and happiness. The aspirations of their builders make these beautiful cities less relics of the past than living guideposts for future biophilic urbanism [8] (Chapter 6, pp. 146-148).

We see the complex multiple fractal design techniques applied in traditional artifacts, ornamentation, and art. Despite radically different appearances, the traditional architectures of the world seem to deliver the fractal dimensionalities needed for optimal human well-being. People have known about these beneficial design elements for millennia. Yet despite their great advantages, not least of which are energy efficiency and sustainability, these design typologies were increasingly abandoned after World War I in the name of Modernity.

Indeed, Chicago Architect Louis Sullivan (1856-1924) actually suggested in his Kindergarten Chats that we live "for our aesthetic good" for a period without ornament, that "we might safely inquire to what extent a decorative application of ornament would enhance the beauty of our structures-what new charm it would give them" [132]. Sullivan was right. Just because something is new it is not necessarily better. We are neuroaesthetically over-stressed in ornament-bare, post-World War II architecture and urbanism, and this is detrimental to our health [133-136].

It is not unreasonable to demand built environments that influence human health positively. To that end, this paper dissected the visual experience of pedestrian urban environments, leading to the conclusion that aesthetic experience is of the essence. Even the earliest phases of visual processing are sensitive to the presence or absence of fractals. This initial perceptual processing is significant in producing a sense of well-being. The salutogenic effect of multiple fractal environments can contribute to recovery from physical or mental illness or injury. Conversely, the lack of fractal aesthetics in unnatural environments puts a strain on the visual system, inducing negative responses such as headaches [137].

The data reviewed here show that we fundamentally need to change how we design the built environment. It is time for people to place urban well-being above aesthetic ideology; the durability and long-term reusability of urban fabric above fashion. Changing built environments-from "old-fashioned" to new, slick, and shiny-is a huge mistake, as people all over the world realize that we need emotional nourishment from the environment around us. "Old-fashioned" surroundings could likely contain essential healing qualities.

We deserve to walk down a street that is beautiful, as judged by our biology, not by some imposed stylistic criterion. We deserve to be protected from the negative psychological reactions caused by experiencing neuroaesthetically inappropriate if not harmful 
design. Based on our latest scientific understanding of perception, we need to reclaim the appropriate and practical design toolkits of past generations to accomplish these ends. Only then will we be able to build places for the greatest well-being of the greatest number of users.

One point needs clearing up: the evidence does not impose the mummification of older buildings and urban fabric, but instead offers the possibility of properly building new traditional buildings that are as beautiful as those of any time. As far as materials, any economically-advantageous material should be employed; but we should not keep to the same narrow selection of industrial-modernist materials if they are inferior to older methods of construction in their durability and functionality.

This paper provides clients and decision makers with an extremely useful and solid scientific basis for making the correct design decisions. Façades are just one out of many things one can change, and it is a feasible change that one can make relatively quickly (more easily than changing the urban plan). Rather than habitually continuing the 100-year course of urban-disruptive, fractal-absent, stress-inducing design, we urge society to return to the ongoing 5000-year urban experiment. We call on architects, governments, and private investors around the world to take action and:

- Preserve appropriate buildings that indubitably enhance human well-being.

- Enhance and transform the façades of buildings that provide no pre-attentive stimulation or are acknowledged to generate stress.

- Remove poorly-built buildings whose appearance is acknowledged to generate stress or which otherwise pose a threat to human well-being, both physical and emotional.

- Build beautiful, durable, and long-term useful new buildings and urban fabric that conform to the most basic visual aesthetic experiential needs of humans.

Good architecture should be gauged by what it does for the common good-for all of us. There is nothing inauthentic about making spaces that people feel comfortable in. Urban and architectural design should be immediately perceived as "welcoming", "compassionate", and "friendly" by every user [138].

\section{Supplemental Information: Literature Survey}

\subsection{Urban and Neuroaesthetic Anxiety, Stress, and Wellbeing}

Neuroaesthetics studies aesthetic experiences on both the behavioral and neural levels. Empirical aesthetics, and neuroaesthetics in particular, are a prime example for the fruitful integration of the humanities and the sciences [56]. There is no doubt of the advantages of this approach when it comes to studying aesthetic experience in urban form. Yet because this is such a "pedestrian" idea (pun intended), urban neuroaesthetics have been taken for granted by practitioners and researchers alike until now. This literature survey therefore outlines some of the conceptual and technical frameworks within which resides the question, "What happens in your brain when you walk down the street?"

Urban stress has been discussed for a long time [139]. But there are few signs that our cities are undergoing the transformative, structural changes necessary to promote well-being. New data-driven and technology-enabled approaches to neurourbanism are only now beginning to "connect the dots" [140].

An interest in the finer grain of connection between city environments and recognized mental health states such as anxiety, depression, schizophrenia, and other afflictions of the city/psychosis nexus such as exhaustion, weariness, melancholy, and uncertainty, is beginning to emerge [141,142].

The spatial perspective encourages us to focus on the multi- or inter-sensorial perception of the city, looking at how we experience it. Since cities produce "a flow of experiences" that people encounter, studying the urban experience requires paying attention to transitional moments in the urban environment's physical aspects [143]. The input provided by the urban architectural features of the city are central to the experience of urban space, and the wrong information and stimuli can make a place "psychotoxic" [144]. 
Although a good number of studies examine urban green spaces and planting, they appear to be more studies in correlation than causation. Typically, they make no mention of the (fractal) mathematics of perception, biophilia, and certainly not traditional design, even when they examine evidence linking urban design to emotional restoration and wellbeing [145-157]. Some of the most advanced research engages in the taxonomy of urban properties rather than the underlying perceptual causation regarding the human experience [158-160]. A number of studies propagate well-known, but not fully proven theories (Lynch) [161]. Almost all studies are self-limited to Modernist stylistic forms [162,163], however, and promote the standard litany of more green, more parks, and less traffic $[164,165]$.

Recent experimental studies began examining the neuroaesthetics of the built environment [166-170]. But most offer a perspective almost completely limited to modernist aesthetics and fail to consider traditional design let alone the fractal mathematics of perception [3,171-180]. So much so, that decontextualizing neuroaesthetics may create biases about its future possibilities and developments [181].

\subsection{The Pedestrian Experience}

According to a millennial-old philosophical debate, aesthetic experience has been connected to knowledge acquisition. It opens a path to further experience-and continuing walking. Research suggests that aesthetic appreciation represents hedonic feedback as walking progresses, and a strong association between aesthetic appreciation and the activation of the dopaminergic reward-related circuits in the brain. The sense of beauty might be fundamental to balancing perception of informationally profitable stimuli and action, enabling us to avoid automatic reactions and tolerate transient states of sensory uncertainty and memory updating as we walk down a street, computing predictive representations of where we go next [182].

Everyday life includes a multitude of movements involving the eyes, the arms, or the legs. We may walk to the toaster, gaze at the slots on its top, slip in two halves of a bagel, and press the "Toast" button. Yet as simple as this daily task may sound, it raises fundamental questions regarding the shared underpinnings of perception and movement neuroscience [183].

Eye movements and locomotion share many underlying neural circuits, while studies sampling eye movements during locomotion reveal the relationships among fixations, saccades, and gait, and these are supported by the overlap in locomotor and saccadic neural circuitry [184]. The correlation of saccadic eye movement and walking is so predictable that a reliable predictive algorithm already exists [185-189].

The human visual system is influenced by the body's locomotion. Walking and eye movements are related such that the saccade rate is significantly linked to walking speed in (day)light; and blinks and saccades occur preferentially in walking at the moment when both feet touch the ground [190]. Obviously, wayfinding and orientation rely heavily on perception and are broadly influenced by neuroaesthetics [191-195]. Perhaps most significantly, location dominates the experience of memory, bringing urban neuroaesthetics even deeper into the individual psyche and highlighting the significance of locational neuroaesthetics and urban design and place-making for legible cities [196].

\subsection{Urban Eye Tracking and Visual Attention Software (VAS)}

New geospatial technologies and ubiquitous sensing allow new data regarding individual aesthetic processing for analysis and interpretation of spatial perceptions and experiences of public spaces [197]. Virtual reality and mobile electroencephalography are the most commonly used neuroscientific urban research methods [198]. Also used are the physical metrics of spatial characteristics, the size of stimuli, the rhythm of mobility; and the biophysical heart rate, galvanic skin response, and eye-tracking measurements [199].

To study people's behavior in dynamic environments and to observe the pedestrians' perceptions in the field, mobile eye tracking glasses pick up data regarding the distribution 
of human gaze on moving and still objects. While walking along the street, the subjects fixate on objects located mostly between 1 and $55 \mathrm{~m}$, focusing predominantly on people, sidewalks, and buildings. They then look at moving and stationary vehicles, and finally at the standard street miscellanea of street furniture, bicycles, and dogs [200].

Eye tracking emulation software such as 3M's Visual Attention Software (3M-VAS) has been shown to predict human visual attention with about $92 \%$ accuracy. Already recognized as a promising urban design tool, it can reveal pre-attentive processing of visual stimuli with a very high degree of accuracy [201-203].

Eye-tracking can be used to identify both the attentive elements of a design and the lengths of attention. Since gaze distributions can show how people visually engage with the design, it can capture participants' visual explorations and experiences, and their visual engagement with facades or urban street edges [204].

While many concepts have been developed in theoretical terms, studies using new psychophysiological measurements and neuroimaging have not yet verified many of the theories. While much research appears to confirm what science already knows, we are reminded that correlation is not causation. The research appears to be delimited by the researchers' understanding of psychological process, their architectural literacy, the knowledge of perception science, and the added layer of accepting 20th century theories of urbanism and contemporary design ideologies as fact. Hollander and Sussman's Urban Experience and Design: Contemporary Perspectives on Improving the Public Realm corrects and identifies many of these pitfalls [205].

Some studies exploring new devices and software such as Electroencephalograms and eye tracking appear to be more along the lines of equipment calibration reports. Some appear to confirm scientists' aesthetic biases or research interests rather than explaining the causality behind the results [206-211]. Some of the research confirms previous findings $[212,213]$, yet the claims regarding the measured results may still require additional interpretation [214]. Most do not discuss the temporal sequence of visual perception, which parses out intuitive, not-conscious perceptive processes from intellectualized ones [215,216].

Many articles confirm what we already know-that people are thigmotaxic (move along a wall for protection) and that urban street edges are the most visually engaged component of streets; that people like countryside and landscaping; and that people visually engage with the ground floor street edge more than with their upper floors. Scientists without a background in architectural- or urban design appear challenged by why, in their experiments, the perception of buildings—-the key component of urban design-yielded mixed results [217-220].

Little research has evaluated traditional architecture [221], indicating that it might prove difficult for architects to successfully adapt their designs to how people untrained in Modernist design actually perceive built environments [222]. In any event, it appears that to properly interpret the findings, the researcher must have some knowledge of biophilia and/or be architecturally literate [223].

There were studies in eye tracking in parking garages [224], engaging with ticket vending machines [225], reading freeway signage [226], transit maps [227], and leisure behavior research [228]. Eye tracking in urban visual environment opens the door to exploring the effects on mental and other health concerns of visual environment "pollution" [229]. Conjoined with innovative mapping techniques, eye-tracking tools enhance the interpretability of real outdoor environmental experiences [230].

At times, emotions, activities, and mental and physiological effects are not clearly distinguished. Identifying correlations in network science, ecosystems studies, statistical physics, and information theory does not directly enable the drawing of genuinely applicable conclusions regarding qualitative human experience and the design of the built environment.

Ultimately, classic urban design principles-such as horizontal-vertical rhythms, variety, active ground floor, and tactile materials-are a coherent set of principles that play a significant role in people's experience of a streetscape. But identifying these principles 
has not led researchers to the necessary conclusions with regard to their application. Not knowing the multiple fractal properties of traditional design styles-and believing such styles to be "old fashioned" and therefore outside the scope of their interests-has resulted in researchers overlooking two facts. (1). That, due to their lack of visual fractal properties, non-traditional styles simply do not and cannot deliver the same types and qualities of visual experience as traditional designs do [231-234]. (2). That the preferred experiential design principles are best, if not exclusively, articulated in traditional streetscape and building designs [235-237].

Author Contributions: Conceptualization, N.H.B. and N.A.S.; methodology, A.A.B. and R.P.T.; investigation, N.H.B.; resources, N.H.B.; writing—original draft preparation, N.H.B.; writing-review and editing, A.A.B., N.H.B., N.A.S., R.P.T.; visualization, N.H.B.; supervision, N.H.B.; project administration, N.A.S. All authors have read and agreed to the published version of the manuscript.

Funding: This research received no external funding A.B. was supported by the Deutsche Forschungsgemeinschaft (DFG, German Research Foundation) \# 461354985.

Acknowledgments: The members of this research group belong to the Fractal Round Table of the Classic planning Institute. Thanks to Kelly Canavan of the 3M Corporation for providing access to Visual Attention Software.

Conflicts of Interest: The authors declare no conflict of interest.

\section{References}

1. Fischmeister, F.P.; Martins, M.J.D.; Beisteiner, R.; Fitch, W.T. Self-similarity and Recursion as Default Modes in Human Cognition. Cortex 2016, 97, 183-201. [CrossRef] [PubMed]

2. Martins, M.J.; Fischmeister, F.P.; Puig-Waldmüller, E.; Oh, J.; Geissler, A.; S Robinson, S.; Fitch, W.T.; Beisteiner, R. Fractal image perception provides novel insights into hierarchical cognition. Neuroimage 2014, 96, 300-308. [CrossRef]

3. Salingaros, N.A. Fractal Art and Architecture Reduce Physiological Stress. J. Biourbanism 2012, 2, 11-28.

4. Lavdas, A.; Salingaros, N.; Sussman, A. Visual Attention Software: A new tool for understanding the 'subliminal' experience of the built environment. Appl. Sci. 2021, 11, 6197. [CrossRef]

5. Salingaros, N.; Sussman, A. Biometric pilot-studies reveal the arrangement and shape of windows on a traditional façade to be implicitly 'engaging', whereas contemporary façades are not. Urban Sci. 2020, 4, 26. [CrossRef]

6. Sussman, A.; Hollander, J.B. Cognitive Architecture: Designing for How We Respond to the Built Environment, 2nd ed.; Routledge: New York, NY, USA, 2021.

7. Spanjar, G.; Suurenbroek, F. Eye-Tracking the City: Matching the Design of Streetscapes in High-Rise Environments with Users' Visual Experiences. J. Digit. Landsc. Archit. (JoDLA) 2020, 5, 374-385.

8. Buras, N.H. The Art of Classic Planning; Harvard University Press: Cambridge, MA, USA, 2019.

9. Salingaros, N. Rules for Urban Space: Design Patterns Create the Human Scale. J. Urban Res. Dev. 2021, 2, 4-16.

10. Smith, N. Employees Reveal How Stress Affects Their Jobs. Bus. News Dly. 2020. Available online: https://www. businessnewsdaily.com/2267-workplace-stress-health-epidemic-perventable-employee-assistance-programs.html (accessed on 20 August 2021).

11. Jacobs, J. The Death and Life of Great American Cities; Vintage: New York, NY, USA, 2016.

12. Alexander, C. The Timeless Way of Building; Oxford University Press: Oxford, UK, 1979.

13. Wilson, E.O. Biophilia; Harvard University Press: Cambridge, MA, USA, 1984.

14. Ulrich, R.S.; Simons, R.F. Recovery from stress during exposure to everyday outdoor environments. Proc. EDRA 1986, 17, 115-122.

15. Ulrich, R.S. Biophilia, Biophobia and Natural Landscapes. In The Biophilia Hypothesis; Island Press: Washington, DC, USA, 1993.

16. Ulrich, R.S. Natural versus urban scenes: Some psychophysiological effects. Environ. Behav. 1981, 13, 523-556. [CrossRef]

17. Kaplan, R.; Kaplan, S. Attention Restoration Theory. In Cognition and Environment: Functioning in an Uncertain World; Praeger: New York, NY, USA, 1982.

18. Mandelbrot, B.B. The Fractal Geometry of Nature; WH Freeman: New York, NY, USA, 1982.

19. Fairbanks, M.S.; Taylor, R.P. Scaling analysis of spatial and temporal patterns: From the human eye to the foraging albatross. In Non-Linear Dynamical Analysis for the Behavioral Sciences Using Real Data; Taylor and Francis Group: Boca Raton, FL, USA, 2011.

20. Taylor, R.P. Order in Pollock's Chaos. Sci. Am. 2002, 287, 117-121. Available online: http://authenticationinart.org/pdf/ literature/Richard-P.-TaylorOrder-in-Pollocks-Chaos.pdf (accessed on 5 January 2022). [CrossRef]

21. Spehar, B.; Clifford, C.W.; Newell, B.R.; Taylor, R.P. Universal aesthetic of fractals. Comput. Graph. 2003, 27, 813-820. [CrossRef]

22. Spehar, B.; Taylor, R. Fractals in art and nature: Why do we like them? Proc. SPIE 2013, 8651, 865118-1.

23. Bies, A.J.; Blanc-Goldhammer, D.R.; Boydston, C.R.; Taylor, R.P.; Sereno, M.E. Aesthetic responses to exact fractals driven by physical complexity. Front. Hum. Neurosci. 2016, 10, 210. [CrossRef] 
24. Spehar, B.; Walker, N.; Taylor, R.P. Taxonomy of individual variations in aesthetic responses to fractal patterns. Front. Hum. Neurosci. 2016, 10, 350. [CrossRef]

25. Cutting, J.E.; Garvin, J.J. Fractal curves and complexity. Percept. Psychophys. 1987, 42, 365-370. [CrossRef] [PubMed]

26. Marlow, C.A.; Viskontas, I.V.; Matlin, A.; Boydston, C.; Boxer, A.; Taylor, R.P. Temporal structure of human gaze dynamics is invariant during free viewing. PLoS ONE 2015, 10, e0139379. [CrossRef]

27. Moon, P.; Muday, J.; Raynor, S.; Schirillo, J.; Boydston, C.; Fairbanks, M.S.; Taylor, R.P. Fractal images induce fractal pupil dilations and constrictions. Int. J. Psychophysiol. 2014, 93, 316-321. [CrossRef]

28. Brouwer, A.; Knill, D.C. Humans use visual and remembered information about object location to plan pointing movements. J. Vis. 2009, 9, 1-19. [CrossRef] [PubMed]

29. Taylor, R.P.; Juliani, A.W.; Bies, A.J.; Boydston, C.; Spehar, B.; Sereno, M.E. The Implications of Fractal Fluency for Biophilic Architecture. J. Biourbanism 2017, 6, 23-40.

30. Hagerhall, C.M.; Laike, T.; Küller, M.; Marcheschi, E.; Boydston, C.; Taylor, R.P. Human Physiological Benefits of Viewing Nature: EEG Response to Exact and Statistical Fractal Patterns. J. Nonlinear Dyn. Psychol. Life Sci. 2015, 19, 1-12.

31. Isherwood, Z.J.; Schira, M.M.; Spehar, B. The tuning of human cortex to variations in $1 / \mathrm{f}$ amplitude spectra and fractal properties of synthetic noise images. Neuroimage 2016, 146, 642-657. [CrossRef]

32. Spehar, B.; Wong, S.; van de Klundert, S.; Lui, J.; Clifford, C.W.G.; Taylor, R.P. Beauty and the beholder: The role of visual sensitivity in visual preference. Front. Hum. Neurosci. 2015, 9, 1-12. [CrossRef] [PubMed]

33. Juliani, A.W.; Bies, A.J.; Boydston, C.R.; Taylor, R.P.; Sereno, M.E. Navigation performance in virtual environments varies with fractal dimension of landscape. J. Environ. Psychol. 2016, 47, 155-165. [CrossRef]

34. Rogowitz, B.E.; Voss, R.F. Shape perception and low-dimension fractal boundary contours. Human vision and electronic imaging: Models, methods, and applications. Int. Soc. Opt. Photonics 1990, 1249, 387-394.

35. Bies, A.; Kikumoto, A.; Boydston, C.; Greeenfield, A.; Chauvin, K.; Taylor, R.; Sereno, M. Percepts from noise patterns: The role of fractal dimension in object pareidolia. J. Vis. 2016, 16, 790. [CrossRef]

36. Bies, A.J.; Wekselblatt, J.; Boydston, C.R.; Taylor, R.P.; Sereno, M.E. The effects of visual scene complexity on human visual cortex. In Proceedings of the 2015 Neuroscience Meeting, Chicago, IL, USA, 19-23 October 2019; Society for Neuroscience: Chicago, IL, USA; Volume 21.

37. Taylor, R.P.; Martin, T.P.; Montgomery, R.D.; Smith, J.H.; Micolich, A.P.; Boydston, C.; Scannell, B.C.; Fairbanks, M.S.; Spehar, B. Seeing shapes in seemingly random spatial patterns: Fractal analysis of Rorschach inkblots. PLoS ONE 2017, 12, e0171289. [CrossRef]

38. Taylor, R.P. Splashdown. New Sci. 1998, 2144, 30-31.

39. Aks, D.; Sprott, J. Quantifying aesthetic preference for chaotic patterns. Empir. Stud. Arts 1996, 14, 1-16. [CrossRef]

40. Robles, K.; Liaw, N.; Taylor, R.P.; Baldwin, D.; Sereno, M.E. A Shaded Fractal Aesthetic Across Development. Humanit. Soc. Sci. Commun. 2020, 7, 158. [CrossRef]

41. Billock, V.A. Neural acclimation to $1 / \mathrm{f}$ spatial frequency spectra in natural images transduced by human visual system. Physical D 2000, 137, 379. [CrossRef]

42. Hagerhall, C.M.; Purcell, T.; Taylor, R.P. Fractal dimension of landscape silhouette outlines as a predictor of landscape preference J. Environ. Psychol. 2004, 24, 247-255. [CrossRef]

43. Taylor, R.P. Reduction of physiological stress using fractal art and architecture. Leonardo 2006, 39, 245-251. [CrossRef]

44. Taylor, R.P.; Sprott, J.C. Biophilic fractals and the visual journey of organic Screen-savers. J. Non-Linear Dyn. Psychol. Life Sci. 2008, 12, 117-129.

45. Abboushi, B.; Elzeyadi, I.; Taylor, R.P.; Sereno, M.E. Fractals in Architecture: The Visual Interest and Mood Response to Projected Fractal Light Patterns in Interior Spaces. J. Environ. Psychol. 2018, 61, 57-70. [CrossRef]

46. Stamps, A.E. Fractals, skylines, nature and beauty. Landsc. Urban Plan 2002, 60, 163-184. [CrossRef]

47. Pyankova, S.D.; Chertkova, Y.D.; Scobeyeva, V.A.; Chertkova, E.R. Influence of Genetic Factors on Perception of Self-similar Objects. Psychol. Subculture Phenomenol. Contemp. Tendencies Dev. 2019, 1, 530-537. [CrossRef]

48. Richards, R. A new aesthetic for environmental awareness: Chaos theory, the beauty of nature, and our broader humanistic identity. J. Humanist. Psychol. 2001, 41, 59-95. [CrossRef]

49. Street, N.; Forsythe, A.; Reilly, R.G.; Taylor, R.P.; Boydston, C.; Helmy, M.S. A complex story: Universal preference vs. individual differences shaping aesthetic response to fractals patterns? Front. Hum. Neurosci. 2016, 10, 213. [CrossRef]

50. Roe, E.; Bies, A.J.; Watterson, W.J.; Montgomery, R.D.; Boydston, C.R.; Sereno, M.E.; Taylor, R.P. Fractal Solar Cells: A Marriage between Aesthetic and Electrical Performance. PLoS ONE 2020, 15, e0229945. [CrossRef]

51. Abboushi, B.; Elzeyadi, I.; Van Den Wymelenberg, B.; Taylor, R.P.; Sereno, M.E.; Jacobsen, G. Investigating Visual Comfort, Visual Interest of Sunlight Patterns and View Quality Under Different Window Conditions in an Open Plan Office. J. Illum. Eng. Soc. 2020, 17, 321-337. [CrossRef]

52. Boon, J.P.; Casti, J.; Taylor, R.P. Artistic Forms and Complexity. J. Nonlinear Dyn. Psychol. Life Sci. 2011, 15, $265-283$.

53. Viengkham, C.; Isherwood, Z.; Spehar, B. Fractal Scaling Properties as Aesthetic Primitives in Vision and Touch. Axiomathes 2019. [CrossRef]

54. Taylor, R.P. The Potential of Biophilic Fractal Designs to Promote Health and Performance: A Review of Experiments and Applications. J. Sustain. 2021, 13, 823. [CrossRef] 
55. Hagerhall, C.M.; Laike, T.; Taylor, R.P.; Küller, M.; Küller, R.; Martin, T.P. Investigation of EEG response to fractal patterns. Percept 2008, 37, 1488-1494. [CrossRef]

56. Barron, F.; Welsh, G.S. Artistic perception as a possible factor in personality style: Its measurement by a figure preference test. J. Psychol. 1952, 33, 199-203. [CrossRef]

57. Child, I.L. Personal preferences as an expression of aesthetic sensitivity. J. Personal. 1962, 30, 496-512. [CrossRef]

58. Goetz, K.O.; Lynn, R.; Borisy, A.R.; Eysenck, H.J. A new visual aesthetic sensitivity test: I. Construction and psychometric properties. Percept. Mot. Ski. 1979, 49, 795-802. [CrossRef]

59. Wilson, A.; Chatterjee, A. The assessment of preference for balance: Introducing a new test. Empir. Stud. Arts 2005, 23, 165-180. [CrossRef]

60. Pearce, M.T.; Zaidel, D.W.; Vartanian, O.; Skov, M.; Leder, H.; Chatterjee, A.; Nadal, M. Neuroaesthetics: The cognitive neuroscience of aesthetic experience. Perspect. Psychol. Sci. 2016, 11, 265-279. [CrossRef] [PubMed]

61. Fechner, G.T. Vorschule der Ästhetik; Breitkopf und Härtel: Leipzig, Germany, 1876.

62. Berlyne, D.E. Aesthetics and Psychobiology; Appleton-Century-Crofts: New York, NY, USA, 1974.

63. Berlyne, D.E. (Ed.) Studies in the New Experimental Aesthetics: Steps Towards an Objective Psychology of Aesthetic Appreciation; Hemisphere Publishing Corporation: Washington DC., USA, 1974.

64. Reber, R.; Schwarz, N.; Winkielman, P. Processing fluency and aesthetic pleasure: Is beauty in the perceiver's processing experience? Personal. Soc. Psychol. Rev. 2004, 8, 364-382. [CrossRef]

65. Brielmann, A.A.; Dayan, P. Introducing a computational model of aesthetic value. Psychol. Rev. 2021; in press.

66. Armstrong, T.; Detweiler-Bedell, B. Beauty as an emotion: The exhilarating prospect of mastering a challenging world. Rev. Gen. Psychol. 2008, 12, 305-329. [CrossRef]

67. Gallese, V.; Freedberg, D. Mirror and canonical neurons are crucial elements in esthetic response. Trends Cogn. Sci. 2007, 11, 411. [CrossRef]

68. Chatterjee, A.; Vartanian, O. Neuroaesthetics. Trends Cogn. Sci. 2014, 18, 370-375. [CrossRef]

69. Pelowski, M.; Markey, P.S.; Forster, M.; Gerger, G.; Leder, H. Move me, astonish me delight my eyes and brain: The Vienna integrated model of top-down and bottom-up processes in art perception (VIMAP) and corresponding affective, evaluative, and neurophysiological correlates. Phys. Life Rev. 2017, 21, 80-125. [CrossRef]

70. Balling, J.D.; Falk, J.H. Development of visual preference for natural environments. Environ. Behav. 1982, 14, 5-28. [CrossRef]

71. Kaplan, S. Aesthetics, affect, and cognition. Environ. Behav. 1987, 19, 3-32. [CrossRef]

72. Kirk, U.; Skov, M.; Christensen, M.S.; Nygaard, N. Brain correlates of aesthetic expertise: A parametric fMRI study. Brain Cogn. 2009, 69, 306315. [CrossRef] [PubMed]

73. Reimann, M.; Zaichkowsky, J.; Neuhaus, C.; Bender, T.; Weber, B. Aesthetic package design: A behavioral, neural, and psychological investigation. J. Consum. Psychol. 2010, 20, 431-441. [CrossRef]

74. Van der Laan, L.N.; De Ridder, D.T.D.; Viergever, M.A.; Smeets, P.A.M. Appearance Matters: Neural Correlates of Food Choice and Packaging Aesthetics. PLoS ONE 2012, 7, e41738. [CrossRef]

75. Vartanian, O.; Navarrete, G.; Chatterjee, A.; Fich, L.B.; Leder, H.; Modroño, C.; Nadal, M.; Rostrup, N.; Skov, M. Impact of contour on aesthetic judgments and approach avoidance decisions in architecture. Proc. Natl. Acad. Sci. USA 2013, 110 (Suppl. 2), 10446-10453. [CrossRef]

76. Kasprisin, R. Urban Design: The Composition of Complexity; Routledge: New York, NY, USA, 2011.

77. Santayana, G. The Sense of Beauty: Being the Outline of Aesthetic Theory; Charles Scribner's Sons: New York, NY, USA, 1896 ; p. 19.

78. Burke, E. A Philosophical Enquiry into the Origin of our Ideas of the Sublime and the Beautiful; Dodsley: London, UK, 1757.

79. Dewey, J. Art as Experience; Allen \& Unwin: London, UK, 1934.

80. Shusterman, R. The End of Aesthetic Experience. J. Aesthet. Art Crit. 1997, 55, 29-41. [CrossRef]

81. Ishizu, T.; Zeki, S. Toward a Brain-Based Theory of Beauty. PLoS ONE 2011, 6, e21852. [CrossRef]

82. Vessel, E.A.; Maurer, N.; Denker, A.H.; Starr, G.G. Stronger shared taste for natural aesthetic domains than for artifacts of human culture. Cognition 2018, 179, 121-131. [CrossRef]

83. Brielmann, A.A.; Pelli, D.G. Intense beauty requires intense pleasure. Front. Psychol. 2019, 10, 2420. [CrossRef]

84. Bruce Goldstein, E. Sensation and Perception, 8th ed.; Cengage Learning: Belmont, CA, USA, 2009; pp. 5-7.

85. Gutierrez, K. Studies Confirm the Power of Visuals in eLearning. Shift: Disruptive eLearning. Available online: www. shiftelearning.com/blog/bid/350326/studies-confirm-the-power-of-visuals-in-elearning (accessed on 8 July 2014).

86. Gregory, R. Perception. In The Oxford Companion to the Mind; Richard, L., Gregory, R., Zangwill, O.L., Eds.; Oxford University Press: Oxford, UK, 1987; pp. 598-601.

87. Douglas, A. Bernstein. In Essentials of Psychology; Cengage Learning: Belmont, CA, USA, 2010; pp. 123-124.

88. Zhang, W.; He, X.; Lai, S.; Wan, J.; Lai, S.; Zhao, X.; Li, D. Neural Substrates of Embodied Natural Beauty and Social Endowed Beauty: An fMRI Study. Sci. Rep. 2017, 7, 7125. [CrossRef] [PubMed]

89. Zeki, S. The Macro- and Micro- Worlds in Physics and Perception. Prof. Zeki's Musings. Available online: http://profzeki.blogspot. com/2016/09/the-macro-and-micro-worlds-in-physics_8.html (accessed on 30 December 2021).

90. Zeki, S. The Disunity of Consciousness. Trends Cogn. Neurosci. 2003, 7, 214-218. [CrossRef]

91. Zeki, S. "Multiplexing" cells of the visual cortex and the timing enigma of the binding problem. Eur. J. Neurosci. 2020, 52, 4684-4694. [CrossRef] 
92. Dijkstra, N.; Bosch, S.E.; van Gerven, M.A.J. Shared neural mechanisms of visual perception and imagery. Trends Cogn. Sci. 2019, 23, 423-434. [CrossRef] [PubMed]

93. Salti, M.; Monto, S.; Charles, L.; King, J.; Parkkonen, L.; Dehaene, S. Distinct cortical codes and temporal dynamics for conscious and unconscious percepts. elife 2015, 4, e05652. [CrossRef] [PubMed]

94. Hermann, K.; Singh, S.; Rosenthal, I.; Pantazis, D.; Conway, B. Temporal dynamics of the neural representation of hue and luminance contrast. bioRxiv 2020, preprint. [CrossRef]

95. Wutz, A.; Muschter, E.; van Koningsbruggen, M.G.; Weisz, N.; Melcher, D. Temporal integration windows in neural processing and perception aligned to saccadic eye movements. Curr. Biol. 2016, 26, 1659-1668. [CrossRef]

96. Nothdurft, H.C. Cued visual selection-a tool to study the dynamics of neural processes in perception. VPL Rep. 2017, 6, 1-24.

97. Cichy, R.; Kriegeskorte, N.; van den Bosch, J.; Jozwik, K.; Charest, I. Characterizing the spatio-temporal dynamics of behaviorrelated neural activity during human visual object perception. J. Vis. 2017, 17, 1341. [CrossRef]

98. Cichy, R.M.; Kriegeskorte, N.; Jozwik, K.M.; van den Bosch, J.J.F.; Charest, I. The spatiotemporal neural dynamics underlying perceived similarity for real-world objects. Neuroimage 2019, 194, 12-24. [CrossRef]

99. Shakespeare, W. Hamlet. Act 2, Scene 2. Available online: http://shakespeare.mit.edu/hamlet/full.html (accessed on 30 December 2021).

100. Suardi, A.; Sotgiu, I.; Costa, T.; Cauda, F.; Rusconi, M. The neural correlates of happiness: A review of PET and fMRI studies using autobiographical recall methods. Cogn. Affect. Behav. Neurosci. 2016, 16, 383-392. [CrossRef] [PubMed]

101. Field, D.J.; Brady, N. Visual sensitivity, blur and the sources of variability in the amplitude spectra of natural scenes. Vis. Res. 1997, 37, 3367-3383. [CrossRef]

102. Knill, D.C.; Field, D.; Kersten, D. Human discrimination of fractal images. J. Opt. Soc. Am. 1990, 77, 1113-1123. [CrossRef] [PubMed]

103. Geake, J.; Landini, G. Individual differences in the perception of fractal curves. Fractals 1997, 5, 129-143. [CrossRef]

104. Mikiten, T.M.; Salingaros, N.; Yu, H.-S. Pavements as Embodiments of Meaning for a Fractal Mind. Nexus Netw. J. 2000, 2, 61-72. [CrossRef]

105. Salingaros, N. Adaptive Versus Random Complexity. New Des. Ideas 2018, 2, 51-61.

106. Viswanathan, G.M.; Afanasyev, V.; Buldyrev, S.V.; Murphy, E.J.; Prince, P.A.; Stanley, H.E. Lévy flight search patterns of wandering albatrosses. Nature 1996, 381, 413-415. [CrossRef]

107. Démuthová, S.; Démuth, A. Evolutionary and Cognitive Aspects of Beauty (Attractiveness). Kaygl 2017, 28, 145-158. [CrossRef]

108. Taylor, R.P.; Spehar, B.; von Donkelaar, P.; Hagerhall, C.M. Perceptual and physiological responses to Jackson Pollock's fractals. Front. Hum. Neurosci. 2011, 5, 1-13. [CrossRef] [PubMed]

109. Salingaros, N.A. The biophilic healing index predicts effects of the built environment on our wellbeing. J. Biourbanism. 2019, 8, 13-34.

110. Gegenfurtner, K.R. The interaction between vision and eye movements. Perception 2016, 45, 1333-1357. [CrossRef]

111. Gaspelin, N.; Luck, S.J. “Top-down" does not mean "voluntary". J. Cogn. 2018, 1, 25. [CrossRef]

112. Rauss, K.; Pourtois, G. What is bottom-up and what is top-down in predictive coding? Front. Psychol. 2013, 4, 276. [CrossRef]

113. Shea, N. Distinguishing top-down from bottom-up effects. In Perception and Its Modalities; Biggs, S., Matthen, M., Stokes, D., Eds.; Oxford University Press: Oxford, UK, 2015; pp. 73-91.

114. Salingaros, N.A. Design Methods, Emergence, and Collective Intelligence. Katarxis 2004, 3. Available online: http: / / fluxusfoundation.com/design-methods-emergence-and-collective-intelligence (accessed on 30 December 2021).

115. Jacques, C.; Rossion, B. The speed of individual face categorization. Psychol. Sci. 2006, 17, 485-492. [CrossRef]

116. Wolfe, J.M.; Võ, M.L.H.; Evans, K.K.; Greene, M.R. Visual search in scenes involves selective and nonselective pathways. Trends Cogn. Sci. 2011, 15, 77-84. [CrossRef]

117. Mehaffy, M.; Salingaros, N. Symmetry in architecture: Toward an overdue reassessment. Symmetry: Cult. Sci. 2021, 32, 311-343. [CrossRef]

118. Mallgrave, H.F. The Architect's Brain: Neuroscience, Creativity, and Architecture; Wiley-Blackwell: New York, NY, USA, 2011.

119. Mallgrave, H.F. Architecture and Embodiment: The Implications of the New Sciences and Humanities for Design; Routledge: London, UK, 2013.

120. Robinson, S.; Pallasmaa, J. (Eds.) Mind in Architecture: Neuroscience, Embodiment, and the Future of Design; MIT Press: Cambridge, MA, USA, 2015.

121. Goldhagen, S.W. Welcome to Your World: How the Built Environment Shapes Our Lives; HarperCollins: New York, NY, USA, 2017.

122. Hamilton, D.K.; Watkins, D.H. Evidence-Based Design for Multiple Building Types; Wiley: New York, NY, USA, 2008.

123. Rhea, C.K.; Kiefer, A.W.; Wittstein, M.W.; Leonard, K.B.; MacPherson, R.P.; Wright, W.G.; Haran, F.J. Fractal gait patterns are retained after entrainment to a fractal stimulus. PLOS ONE 2014, 9, e106755. [CrossRef] [PubMed]

124. Burtan, D.; Burn, J.F.; Leonards, U. Nature benefits revisited: Differences in gait kinematics between nature and urban images disappear when image types are controlled for likeability. PLOS ONE 2021, 16, e0256635. [CrossRef]

125. Burtan, D.; Joyce, K.; Burn, J.F.; Handy, T.C.; Ho, S.; Leonards, U. The nature effect in motion: Visual exposure to environmental scenes impacts cognitive load and human gait kinematics. R. Soc. Open Sci. 2021, 8, 201100. [CrossRef]

126. Faust, N.T.; Chatterjee, A.; Christopoulos, G.I. Beauty in the eyes and the hand of the beholder: Eye and hand movements' differential responses to facial attractiveness. J. Exp. Soc. Psychol. 2019, 85, 103884. [CrossRef] 
127. Salingaros, N. Principles of Urban Structure; Sustasis Press: Portland, OR, USA, 2005.

128. Salingaros, N. Applications of the Golden Mean to Architecture. In Symmetry: Culture and Science; Katona, V., Darvas, G., Eds.; Symmetrion: Budapest, Hungary, 2018; Volume 29, pp. 329-351.

129. Salingaros, N. A Theory of Architecture; Sustasis Press: Portland, OR, USA, 2006.

130. Schaffer, L.J. Callistics: The Fractal (Mathematical) Nature of Beauty. Ph.D. Thesis, City University of New York, New York, NY, USA, 1999

131. Salingaros, N. Hierarchical Cooperation in Architecture, and the Mathematical Necessity for Ornament. J. Archit. Plan. Res. 2000, $17,221-235$.

132. Sullivan, L. Ornament in architecture, The Engineering Magazine III: 5 (August 1892). In Kindergarten Chats Other Writings; Wittenborn \& Schultz: New York, NY, USA, 1947.

133. Wilkins, A.J. A physiological basis for visual discomfort: Application in lighting design. Lighting Res. Technol. 2016, 48, 44-54. [CrossRef]

134. Wilkins, A.J. Looking at buildings can actually give people headaches. Conversation 2018. Available online: https://www.cnn. $\mathrm{com} /$ style/article/why-looking-at-buildings-can-give-people-headaches/index.html (accessed on 30 December 2021).

135. Salingaros, N. Symmetry gives meaning to architecture. Symmetry Cult. Sci. 2020, 31, 231-260. [CrossRef]

136. Salingaros, N. Why Monotonous Repetition is Unsatisfying. Permac. Res. Inst. 2012. Available online: http:/ / permaculture.org. au/2012/01/04/why-monotonous-repetition-is-unsatisfying/ (accessed on 30 December 2021).

137. Le, A.T.D.; Payne, J.; Clarke, C.; Kelly, M.A.; Prudenziati, F.; Armsby, E.; Penacchio, O.; Wilkins, A.J. Discomfort from Urban Scenes, Metabolic Consequences. Landsc. Urban Plan 2017, 160, 61. [CrossRef]

138. Salingaros, N.A. Design should follow human biology and psychology. J. Biourbanism 2018, 7, 25-36.

139. Coleman, A. Urban design. World Health 1994, 47, 14-15.

140. Pykett, J.; Osborne, T.; Resch, B. From urban stress to neurourbanism: How should we research city well-being? Ann. Am. Assoc. Geogr. 2020, 110, 1936-1951. [CrossRef]

141. Amin, A.; Richaud, L. Stress and the ecology of urban experience: Migrant mental lives in central Shanghai. Trans. Inst. Br. Geogr. 2020, 45, 862-876. [CrossRef]

142. Söderström, O.; Empson, L.A.; Codeluppi, Z.; Söderström, D.; Baumann, P.S.; Conus, P. Unpacking 'the City': An experience-based approach to the role of urban living in psychosis. Health Place 2016, 42, 104-110. [CrossRef]

143. Winz, M. An atmospheric approach to the city-psychosis nexus. Perspectives for researching embodied urban experiences of people diagnosed with schizophrenia. Ambiances. Environ. Sensib. Archit. Et Espace Urbain 2018, 8. [CrossRef]

144. Golembiewski, J. Architecture, the urban environment and severe psychosis: Aetiology. J. Urban Des. Ment. Health $2017,2,1-3$.

145. Nghiem, T.P.; Wong, K.L.; Jeevanandam, L.; Chang, C.; Tan, L.Y.; Goh, Y.; Carrasco, L.R. Biodiverse urban forests, happy people: Experimental evidence linking perceived biodiversity, restoration, and emotional wellbeing. Urban For. Urban Green. 2021, 59, 127030. [CrossRef]

146. Mayen Huerta, C.; Cafagna, G. Snapshot of the Use of Urban Green Spaces in Mexico City during the COVID-19 Pandemic: A Qualitative Study. Int. J. Environ. Res. Public Health 2021, 18, 4304. [CrossRef]

147. Nawrath, M.; Guenat, S.; Elsey, H.; Dallimer, M. Exploring uncharted territory: Do urban greenspaces support mental health in low-and middle-income countries? Environ. Res. 2020, 16, 110625. [CrossRef] [PubMed]

148. Cooley, S.J.; Robertson, N.; Jones, C.R.; Scordellis, J.A. “Walk to Wellbeing” in Community Mental Health: Urban and Green Space Walks Provide Transferable Biopsychosocial Benefits. Ecopsychology 2021, 13, 84-95. [CrossRef]

149. Baur, J. Campus community gardens and student health: A case study of a campus garden and student well-being. J. Am. Coll. Health 2020, 30, 1-8. [CrossRef]

150. Callaghan, A.; McCombe, G.; Harrold, A.; McMeel, C.; Mills, G.; Moore-Cherry, N.; Cullen, W. The impact of green spaces on mental health in urban settings: A scoping review. J. Ment. Health 2021, 30, 179-193. [CrossRef]

151. Samuelsson, K.; Barthel, S.; Colding, J.; Macassa, G.; Giusti, M. Urban nature as a source of resilience during social distancing amidst the coronavirus pandemic. OSF Prepr. 2020. [CrossRef]

152. Roe, J.; McCay, L. Restorative Cities: Urban Design for Mental Health and Wellbeing; Bloomsbury Publishing: London, UK, 2021.

153. Elsadek, M.; Liu, B.; Xie, J. Window view and relaxation: Viewing green space from a high-rise estate improves urban dwellers' wellbeing. Urban For. Urban Green. 2020, 55, 126846. [CrossRef]

154. Piga, B.; Morello, E. Environmental design studies on perception and simulation: An urban design approach. Ambiances. Environ. Sensib. Archit. Espace Urbain 2015, 1, 968. [CrossRef]

155. Piga, B.E. Experiential-Walk: Experiencing and Representing the City for Urban Design Purposes. In Experiential Walks for Urban Design; Springer: Cham, Switzerland, 2021; pp. 187-206.

156. AlWaer, H.; Speedie, J.; Cooper, I. Unhealthy Neighbourhood "Syndrome": A Useful Label for Analysing and Providing Advice on Urban Design Decision-Making? Sustainability 2021, 13, 6232. [CrossRef]

157. Bostanci, S.H. A Review of Neuroaesthetics Researches Related to Urban Experience. ICOMEP 2016. In Proceedings of the International Congress of Management Economy and Policy, Istanbul, Turkey, 26-27 November 2016; pp. 4037-4050.

158. Knöll, M.; Neuheuser, K.; Cleff, T.; Rudolph-Cleff, A. A tool to predict perceived urban stress in open public spaces. Environ. Plan. B Urban Anal. City Sci. 2018, 45, 797-813. [CrossRef]

159. Jackson, L.E. The relationship of urban design to human health and condition. Landsc. Urban Plan. 2003, 64, 191-200. [CrossRef] 
160. McCay, L.; Bremer, I.; Endale, T.; Jannati, M.; Yi, J. Urban design and mental health. Urban Ment. Health 2019, 32, 1-3.

161. Christofi, M.; Katsaros, M.; Kotsopoulos, S.D. Form follows brain function: A computational mapping approach. Procedia Manuf. 2020, 44, 108-115. [CrossRef]

162. Krokowska, J. Healing architecture: Exploration of mental well-being in an urban context. In Degree Project in Architecture; Lund University: Lund, Sweden, 2021.

163. Jönsson, J. Urban Refuge-Design for Decreasing Urban Stress in a Dense Environment; Chalmers School of Architecture and Civil Engineering: Stockholm, Sweden, 2020.

164. Koene, M. Urban Stress: Research into the Reduction of Urban Stress through Urban Design; Delft University of Technology: Delft, The Netherlands, 2018.

165. Rybarczyk, G.; Ozbil, A.; Andresen, E.; Hayes, Z. Physiological responses to urban design during bicycling: A naturalistic investigation. Transp. Res. Part F Traffic Psychol. Behav. 2020, 68, 79-93. [CrossRef]

166. Coburn, A.; Vartanian, O.; Kenett, Y.N.; Nadal, M.; Hartung, F.; Hayn-Leichsenring, G.U.; Navarrete, G.; González-Mora, J.L.; Chatterjee, A. Psychological and neural responses to architectural interiors. Cortex 2020, 126, 217-241. [CrossRef]

167. Hayles, C.; Aranda-Mena, G. Well-being in vertical cities: Beyond the aesthetics of nature. In Proceedings of the International Conference of the Architectural Science Association, Melbourne, Australia, 28 November-1 December 2018; pp. 331-338.

168. Coburn, A.; Vartanian, O.; Chatterjee, A. Buildings, beauty, and the brain: A neuroscience of architectural experience. J. Cogn. Neurosci. 2017, 29, 1521-1531. [CrossRef]

169. Coburn, A. Buildings, Beauty, and the Brain: Psychological Responses to Architectural Design. Ph.D. Thesis, University of Cambridge, Cambridge, UK, 2019.

170. Salingaros, N.A. Why we need to "grasp" our surroundings: Object affordance and prehension in architecture. J. Archit. Urban. 2017, 41, 163-169. [CrossRef]

171. Kawabata, H.; Zeki, S. Neural Correlates of Beauty. J. Neurophysiol. 2004, 91, 1699-1705. [CrossRef] [PubMed]

172. Aresta, M.; Salingaros, N.A. The importance of domestic space in the times of COVID-19. Challenges 2021, 12, 27. [CrossRef]

173. Chatterjee, A.; Coburn, A.; Weinberger, A. The neuroaesthetics of architectural spaces. Cogn. Process. 2021, 22, 115-120. [CrossRef] [PubMed]

174. Roberts, A.C.; Christopoulos, G.I.; Car, J.; Soh, C.K.; Lu, M. Psycho-biological factors associated with underground spaces: What can the new era of cognitive neuroscience offer to their study? Tunn. Undergr. Space Technol. 2016, 55, 118-134. [CrossRef]

175. Menezes, K.; de Oliveira-Smith, P.; Woodworth, A.V. (Eds.) Programming for Health and Wellbeing in Architecture; Routledge: London, UK, 2021.

176. Hadley, M. Hurry Up and Wait: Spatial Strategies for Urban Stress Relief. Master's Thesis, University of Waterloo, Waterloo, Canada, 2020.

177. Anzani, A. Reusing Leftovers: Corporeity and Empathy of Places. In Design of the Unfinished; Springer: Cham, Switzerland, 2021; pp. 59-72.

178. Evangelinos, C.; Tscharaktschiew, S. The Valuation of Aesthetic Preferences and Consequences for Urban Transport Infrastructures. Sustainability 2021, 13, 4977. [CrossRef]

179. Shemesh, A.; Leisman, G.; Bar, M.; Grobman, Y.J. A neurocognitive study of the emotional impact of geometrical criteria of architectural space. Archit. Sci. Rev. 2021, 23, 1-4. [CrossRef]

180. Higuera-Trujillo, J.L.; Llinares, C.; Macagno, E. The Cognitive-Emotional Design and Study of Architectural Space: A Scoping Review of Neuroarchitecture and Its Precursor Approaches. Sensors 2021, 21, 2193. [CrossRef]

181. Sarasso, P.; Neppi-Modona, M.; Sacco, K.; Ronga, I. "Stopping for knowledge": The sense of beauty in the perception-action cycle. Neurosci. Biobehav. Rev. 2020, 118, 723-738. [CrossRef]

182. Labaune, O.; Deroche, T.; Teulier, C.; Berret, B. Vigor of reaching, walking, and gazing movements: On the consistency of interindividual differences. J. Neurophysiol. 2020, 123, 234-242. [CrossRef]

183. Srivastava, A.; Ahmad, O.F.; Pacia, C.P.; Hallett, M.; Lungu, C. The relationship between saccades and locomotion. J. Mov. Disord. 2018, 11, 93. [CrossRef]

184. Stuart, S.; Galna, B.; Lord, S.; Rochester, L.; Godfrey, A. Quantifying saccades while walking: Validity of a novel velocity-based algorithm for mobile eye tracking. In Proceedings of the 2014 36th Annual International Conference of the IEEE Engineering in Medicine and Biology Society, Chicago, IL, USA, 26-30 August 2014; pp. 5739-5742.

185. Bahill, A.T.; Adler, D.; Stark, L. Most naturally occurring human saccades have magnitudes of 15 degrees or less. Investig. Ophthalmol. Vis. Sci. 1975, 14, 468-469.

186. Stuart, S.; Hickey, A.; Vitorio, R.; Welman, K.; Foo, S.; Keen, D.; Godfrey, A. Eye-tracker algorithms to detect saccades during static and dynamic tasks: A structured review. Physiol. Meas. 2019, 40, 02TR01. [CrossRef]

187. Marple-Horvat, D.E.; Gilbey, S.L.; Hollands, M.A. A method for automatic identification of saccades from eye movement recordings. J. Neurosci. Methods 1996, 67, 191-195. [CrossRef]

188. Stein, N. Analyzing Visual Perception and Predicting Locomotion using Virtual Reality and Eye Tracking. In Proceedings of the 2021 IEEE Conference on Virtual Reality and 3D User Interfaces Abstracts and Workshops (VRW), Lisbon, Portugal, 27 March-1 April 2021; pp. 727-728.

189. Cao, L.; Chen, X.; Haendel, B.F. Overground walking decreases alpha activity and entrains eye movements in humans. Front. Hum. Neurosci. 2020, 14, 561755. [CrossRef] 
190. Jeffery, K. Urban architecture: A cognitive neuroscience perspective. Des. J. 2019, 22, 853-872. [CrossRef]

191. Li, H.; Xu, J.; Zhang, X.; Ma, F. How Do Subway Signs Affect Pedestrians' Wayfinding Behavior through Visual Short-Term Memory? Sustainability 2021, 13, 6866. [CrossRef]

192. Robinson, T. The Impact of Spatial Boundaries on Wayfinding and Landmark Memory: A Developmental Perspective. Ph.D. Thesis, The University of Alabama, Tuscaloosa, AL, USA, 2020.

193. O'Connor, M.R. Wayfinding: The Science and Mystery of How Humans Navigate the World; St. Martin's Press: New York, NY, USA, 2019.

194. Powers, V.; Mordan, L.; Roberts, D. The Role of Working Memory in Direction Giving and Wayfinding; University Research Symposium, Illinois State University: Normal, IL, USA, 2019.

195. Afrooz, A.; White, D.; Parolin, B. Effects of active and passive exploration of the built environment on memory during wayfinding. Appl. Geogr. 2018, 101, 68-74. [CrossRef]

196. Hollander, J.; Foster, V. Brain responses to architecture and planning: A preliminary neuro-assessment of the pedestrian experience in Boston, Massachusetts. Archit. Sci. Rev. 2016, 59, 474-481. [CrossRef]

197. Buttazzoni, A.; Parker, A.; Minaker, L. Investigating the mental health implications of urban environments with neuroscientific methods and mobile technologies: A systematic literature review. Health Place 2021, 70, 102597. [CrossRef]

198. Christofi, M.; Plastiras, G.; Elia, R.; Tsiourtis, V.; Theocharides, T.; Katsaros, M. Flexible Cities: A Multisided Spatial Application of Tracking Livability of Urban Environment. Int. J. Archit. Environ. Eng. 2021, 15, 98-104.

199. Rudenko, S.; Danilina, N.; Hristov, B. Using a Mobile Eye-Tracking Technology to Explore Pedestrians' Gaze Distribution on Street Space. E3S Web Conf. 2021, 263, 05015, EDP Sciences. Available online: https://www.e3s-conferences.org/articles/e3 sconf/pdf/2021/39/e3sconf_form2021_05015.pdf (accessed on 30 December 2021). [CrossRef]

200. Hollander, J.B.; Sussman, A.; Lowitt, P.; Angus, N.; Situ, M. Eye-tracking emulation software: A promising urban design tool. Archit. Sci. Rev. 2021, 64, 383-393. [CrossRef]

201. Sussman, A.; Ward, J.M. How Biometric Software is Changing How We Understand Architecture-And Ourselves. Common Edge 2021. Available online: https:/ / commonedge.org/how-biometric-software-is-changing-how-we-understand-architectureand-ourselves (accessed on 5 January 2022). [CrossRef]

202. Sussman, A.; Ward, J. Eye-tracking Boston City Hall to better understand human perception and the architectural experience. New Des. Ideas 2019, 3, 53-59.

203. Lee, J.H.; Ostwald, M.J. Fractal Dimension Calculation and Visual Attention Simulation: Assessing the Visual Character of an Architectural Façade. Buildings 2021, 11, 163. [CrossRef]

204. Hollander, J.B.; Sussman, A. (Eds.) Urban Experience and Design: Contemporary Perspectives on Improving the Public Realm; Routledge: London, UK, 2020.

205. Gehl, J. Cities for People; Island Press: Washington, DC, USA, 2010.

206. Nanda, U.; Zhu, X.; Jansen, B.H. Image and emotion: From outcomes to brain behavior. HERD Health Environ. Res. Des. J. 2012, 5, 40-59. [CrossRef] [PubMed]

207. Zou, Z.; Ergan, S.; Fisher-Gewirtzman, D.; Curtis, C. Quantifying the Impact of Urban Form on Human Experience: Experiment Using Virtual Environments and Electroencephalogram. J. Comput. Civ. Eng. 2021, 35, 04021004. [CrossRef]

208. Lisińska-Kuśnierz, M.; Krupa, M. Suitability of eye tracking in assessing the visual perception of architecture-A case study concerning selected projects located in Cologne. Buildings 2020, 10, 20. [CrossRef]

209. Uttley, J.; Simpson, J.; Qasem, H. Eye-Tracking in the real world: Insights about the urban environment. In Handbook of Research on Perception-Driven Approaches to Urban Assessment and Design; Hershey, P.A., Ed.; IGI Global: Hershey, PA, USA, 2018; pp. 368-396.

210. Mantuano, A.; Bernardi, S.; Rupi, F. Cyclist gaze behavior in urban space: An eye-tracking experiment on the bicycle network of Bologna. Case Stud. Transp. Policy 2017, 5, 408-416. [CrossRef]

211. Franěk, M.; Petružálek, J.; Šefara, D. Eye movements in viewing urban images and natural images in diverse vegetation periods. Urban For. Urban Green. 2019, 46, 126477. [CrossRef]

212. Dupont, L.; Ooms, K.; Duchowski, A.T.; Antrop, M.; Van Eetvelde, V. Investigating the visual exploration of the rural-urban gradient using eye-tracking. Spat. Cogn. Comput. 2017, 17, 65-88. [CrossRef]

213. Noland, R.B.; Weiner, M.D.; Gao, D.; Cook, M.P.; Nelessen, A. Eye-tracking technology, visual preference surveys, and urban design: Preliminary evidence of an effective methodology. J. Urban. Int. Res. Placemaking Urban Sustain. 2017, 10, 98-110. [CrossRef]

214. Jam, F.; Azemati, H.R.; Ghanbaran, A.; Esmaily, J.; Ebrahimpour, R. The role of expertise in visual exploration and aesthetic judgment of residential building façades: An eye-tracking study. Psychol. Aesthet. Creat. Arts 2022, in press. [CrossRef]

215. Simpson, J. Three-dimensional gaze projection heat-mapping of outdoor mobile eye-tracking data. Interdiscip. J. Signage Wayfinding 2021, 5, 62-82. Available online: https:/ / eprints.whiterose.ac.uk/172905/1/Simpson\%2C\%202021.pdf (accessed on 30 December 2021). [CrossRef]

216. Simpson, J.; Freeth, M.; Simpson, K.J.; Thwaites, K. Visual engagement with urban street edges: Insights using mobile eye-tracking. J. Urban. Int. Res. Placemaking Urban Sustain. 2019, 12, 259-278. [CrossRef]

217. Li, J.; Zhang, Z.; Jing, F.; Gao, J.; Ma, J.; Shao, G.; Noel, S. An evaluation of urban green space in Shanghai, China, using eye tracking. Urban For. Urban Green. 2020, 56, 126903. [CrossRef]

218. Simpson, J.; Thwaites, K.; Freeth, M. Understanding Visual Engagement with Urban Street Edges along Non-Pedestrianised and Pedestrianised Streets Using Mobile Eye-Tracking. Sustainability 2019, 11, 4251. [CrossRef] 
219. Wang, P.; Yang, W.; Wang, D.; He, Y. Insights into Public Visual Behaviors through Eye-Tracking Tests: A Study Based on National Park System Pilot Area Landscapes. Land 2021, 10, 497. [CrossRef]

220. Hollander, J.B.; Purdy, A.; Wiley, A.; Foster, V.; Jacob, R.J.; Taylor, H.A.; Brunyé, T.T. Seeing the city: Using eye-tracking technology to explore cognitive responses to the built environment. J. Urban. Int. Res. Placemaking Urban Sustain. 2018, 12, 156-171. [CrossRef]

221. Rusnak, M.A.; Rabiega, M. The Potential of Using an Eye Tracker in Architectural Education: Three Perspectives for Ordinary Users, Students and Lecturers. Buildings 2021, 11, 245. [CrossRef]

222. De la Fuente Suárez, L.A. Subjective experience and visual attention to a historic building: A real-world eye-tracking study. Front. Archit. Res. 2020, 9, 774-804. [CrossRef]

223. de Winter, J.; Bazilinskyy, P.; Wesdorp, D.; de Vlam, V.; Hopmans, B.; Visscher, J.; Dodou, D. How do pedestrians distribute their visual attention when walking through a parking garage? An eye-tracking study. Ergonomics 2021, 64, 793-805. [CrossRef] [PubMed]

224. Pashkevich, A.; Szarata, A.; Burghardt, T.E.; Jaremski, R.; Šucha, M. Operation of Public Transportation Ticket Vending Machine in Kraków, Poland: An Eye Tracking Study. Sustainability 2021, 13, 7921. [CrossRef]

225. Shang, T.; Lu, H.; Wu, P.; Wei, Y. Eye-tracking evaluation of exit advance guide signs in highway tunnels in familiar and unfamiliar drivers. Int. J. Environ. Res. Public Health 2021, 18, 6820. [CrossRef]

226. Wang, Z.; Lonsdale, M.D.; Cheung, V. An eye-tracking study examining information search in transit maps: Using China's high-speed railway map as a case study. Inf. Des. J. 2021, 26, 53-72. [CrossRef]

227. Shipley, N.J. Setting Our Sights on Vision: A Rationale and Research Agenda for Integrating Eye-Tracking into Leisure Research. Leis. Sci. 2021, 20, 1-22. [CrossRef]

228. Krupina, A.A.; Bespalov, V.V.; Kovaleva, E.Y.; Bondarenko, E.A. Eye tracking in urban visual environment. Constr. Unique Build. Struct. 2017, 1, 47-56.

229. Kollert, A.; Rutzinger, M.; Bremer, M.; Kaufmann, K.; Bork-Hüffer, T. Mapping of 3D eye-tracking in urban outdoor environments. ISPRS Annals of the Photogrammetry. Remote Sens. Spat. Inf. Sci. 2021, 4, 201-208.

230. Boeing, G. Measuring the complexity of urban form and design. Urban Des. Int. 2018, 23, 281-292. [CrossRef]

231. Vainio, T.; Karppi, I.; Jokinen, A.; Leino, H. Towards Novel Urban Planning Methods-Using Eye-tracking Systems to Understand Human Attention in Urban Environments. In Proceedings of the Extended Abstracts of the 2019 CHI Conference on Human Factors in Computing Systems, Scotland, UK, 4-9 May 2019; pp. 1-8.

232. Hollander, J.B.; Anderson, E.C. The impact of urban façade quality on affective feelings. Archnet-IJAR Int. J. Archit. Res. 2020, 14, 219-232. [CrossRef]

233. Karakas, T.; Yildiz, D. Exploring the influence of the built environment on human experience through a neuroscience approach: A systematic review. Front. Archit. Res. 2020, 9, 236-247. [CrossRef]

234. Olsson, P. Green City Branding-How People Respond to the Built Environment. Master's Thesis, University of Gothenburg, Gothenburg, Sweden, 2020.

235. Tang, M. Analysis of signage using eye-tracking technology. Interdiscip. J. Signage Wayfinding 2020, 4, 61-72. [CrossRef]

236. Hollander, J.B.; Levering, A.P.; Lynch, L.; Foster, V.; Perlo, S.; Jacob, R.J.; Taylor, H.A.; Brunyé, T.T. Cognitive responses to urban environments: Behavioral responses in lab and field conditions. Urban Des. Int. 2020, 8, 1-6. [CrossRef]

237. Hollander, J.B.; Sussman, A.; Purdy Levering, A.; Foster-Karim, C. Using eye-tracking to understand human responses to traditional neighborhood designs. Plan. Pract. Res. 2020, 35, 485-509. [CrossRef] 